Originalveröffentlichung in: Bernd Schneidmüller, Inszenierungen und Rituale des spätmittelalterlichen Reichs. Die Goldene Bulle von 1356 in westeuropäischen Vergleichen, in: Die Goldene Bulle. Politik - Wahrnehmung - Rezeption, Bd. 1, hg. von Ulrike Hohensee/Mathias Lawo/Michael Lindner/Michael Menzel/Olaf B. Rader (Berichte und Abhandlungen, hg. von der Berlin-Brandenburgischen Akademie der Wissenschaften. Sonderband 12), Berlin: Akademie 2009, S. 261-297.

\title{
Inszenierungen und Rituale des spätmittelalterlichen Reichs. Die Goldene Bulle von 1356 in westeuropäischen Vergleichen ${ }^{1}$
}

Normative Texte fixierten im 14. Jahrhundert die politische Ordnung des römischen Imperiums und des französischen Königreichs: Die Goldene Bulle Kaiser Karls IV. und der Kurfürsten von $1356^{2}$ und drei Ordonnanzen König Karls V. von Frankreich von $1374 .{ }^{3}$ Im Kern behielten die Bestimmungen zu Königswahl und Thronfolge ihre Gültigkeit bis zum Ende des Ancien Régime und des Alten Reichs im frühen 19. Jahrhundert. Schon diese Dauerhaftigkeit über 450 Jahre ist erstaunlich genug und bezeugt die Kraft politischer Regulierung in zwei verschiedenen Monarchien. Die Goldene Bulle legte die Wahl der römischen Könige durch sieben Kurfürsten fest, die zentralen Orte des Reichs, die Rechte der Kurfürsten und die ritualisierte Ausgestaltung des politischen Miteinanders. ${ }^{4}$ Die französischen Ordonnanzen sicher-

1 Erweiterter Text des Berliner Vortrags vom 10. Oktober 2006. In einzelnen Partien greife ich einen Katalogartikel von 2006 auf, der hier um die europäischen Vergleiche erweitert wird: Bernd SCHNEIDMÜLLER, Die Aufführung des Reichs. Zeremoniell, Ritual und Performanz in der Goldenen Bulle von 1356, in: Die Kaisermacher. Frankfurt am Main und die Goldene Bulle. 1356-1806. Aufsätze, hg. von Evelyn BROCKHOFF / Michael MATTHäUS (2006) S. 76-92.

2 Benutzte Übersetzung: Quellen zur Verfassungsgeschichte des römisch-deutschen Reiches im Spätmittelalter (1250-1500), hg. von Lorenz WEINRICH (AusgQ A 33, 1983) S. $315-$ 395; vom Wortlaut dieser Ausgabe wird bei eigenen deutschen Übersetzungen gelegentlich abgewichen.

3 Druck bei Marie-Luise HeCKManN, Stellvertreter, Mit- und Ersatzherrscher. Regenten. Generalstatthalter, Kurfürsten und Reichsvikare in Regnum und Imperium vom 13. bis zum frühen 15. Jahrhundert, 2 Bde. (Studien zu den Luxemburgern und ihrer Zeit 9 , 2002) S. 758-778 Nr. 19-23.

4 Zur Goldenen Bulle Karl Zeumer, Die Goldene Bulle Kaiser Karls IV., 2 Bde. (Quellen und Studien zur Verfassungsgeschichte des Deutschen Reiches in Mittelalter und Neuzeit 2, 1908); Bernd-Ulrich Hergemöller, Fürsten, Herren und Städte zu Nürnberg 1355/56. Die Entstehung der „Goldenen Bulle“ Karls IV. (Städteforschung A 13, 1983); Die Kaisermacher. Frankfurt am Main und die Goldene Bulle. 1356-1806. Katalog, hg. 
ten dagegen die Blutsverwandtschaft als Prinzip der Thronfolge, den Ausschluss der Frauen vom Erbrecht am französischen Thron und die vormundschaftliche Regierung für minderjährige Herrscher. Das Krönungsbuch und politische Traktate aus dem Umkreis Karls V. ergänzten diese dynastische Konfiguration. ${ }^{5}$

Innerhalb weniger Jahre wurden also zwei seit Langem praktizierte Herrschaftsmodellierungen für die Zukunft festgeschrieben, die Königswahl im Imperium und die Blutsverwandtschaft in Frankreich. Beide Prinzipien spiegelten die Spannweite monarchischer Ordnung im vormodernen Europa und begleiteten die verschiedenen Entwicklungswege deutscher und französischer Geschichte. Ihre Formen und Folgen wurden in der Forschung immer wieder beschrieben und bewertet.

Erst in jüngerer Zeit erkannte man die zeitliche Nähe und die Abhängigkeiten beider Gesetzeswerke deutlicher. ${ }^{6}$ Bonne, die Mutter König Karls V. von Frankreich, war eine Schwester Kaiser Karls IV., der am französischen Hof erzogen worden war. Als Thronfolger nahm Karl V. an der Verkündung der Goldenen Bulle zu Weihnachten 1356 in Metz teil. Geringe Beachtung fand bisher die zeitliche Nähe zur großen europäischen Pest in der Mitte des 14. Jahrhunderts. Dabei könnten die neuen Verbindlichkeiten auch als Antworten auf diese gigantische Erschütterung gelesen werden. Nicht nur Königin Bonne starb 1349 an der Pest. Gegen tiefe Verunsicherung schufen das kaiserliche Rechtsbuch wie die französischen Krönungsordnungen und Ordonnanzen mit ihren sakralen Fundierungen und den Präsentationen kollegialer Körperlichkeiten neue Gewissheiten.

Die Aussagen zu Wahl, Erbfolge und Krönung gehören zu den Klassikern von Geschichte und Rechtsgeschichte. Dieser Beitrag will sich auf anderes konzentrieren und dabei eher Perspektiven als abgeschlossene Forschungen vorstellen. Es geht um die Ritualisierung politischer Willensbildung und um die Inszenierung des erzielten Konsenses. Das Imperium steht hier im Zentrum; Blicke auf die französische Monar-

von Evelyn BrockhofF / Jan Gerchow / Raphael Gross / August HeuSER (2006). Zu Kaiser Karl IV. vgl. Ferdinand SEIBT, Karl IV. Ein Kaiser in Europa 1346 bis 1378 (1978, ${ }^{5} 1985$ ); Heinz STOOB, Kaiser Karl IV. und seine Zeit (1990); Jörg K. HOENSCH, Die Luxemburger. Eine spätmittelalterliche Dynastie gesamteuropäischer Bedeutung 1308-1437 (Urban-Taschenbücher 407, 2000).

$5 \quad \mathrm{Zu} \mathrm{Karl} \mathrm{V.} \mathrm{von} \mathrm{Frankreich} \mathrm{vgl.} \mathrm{Raymond} \mathrm{CAZELLES,} \mathrm{Société} \mathrm{politique,} \mathrm{noblesse} \mathrm{et} \mathrm{cou-}$ ronne sous Jean le Bon et Charles V (Mémoires et documents publiés par la société de l'École des chartes 28, 1982); Françoise Autrand, Charles V le Sage (1994); Bernd CARQUÉ. Stil und Erinnerung. Französische Hofkunst im Jahrhundert Karls V. und im Zeitalter ihrer Deutung (VMPIG 192, 2004).

6 Autrand, Charles V (wie vorige Anm.) S. 627-629; HeckmanN, Stellvertreter (wie Anm. 3) S. 209 f. 
chie und das englische Parlament wollen die Chancen europäischen Vergleichens ${ }^{7}$ andeuten. Das Thema ,Inszenierung des Reichs' könnte modernistisch anmuten. Das ist nicht der Fall. Vielmehr geht es um Wiederentdeckungen alter Selbstverständlichkeiten. Unsere normativen Texte widmeten dem zeremoniellen Miteinander, der Einfügung der Handelnden in einen politisch-sakralen Raum und der Aufführung des Reichs allergrößte Aufmerksamkeit. Die Forschung folgte solchen Vorlieben der Alten über lange Zeit nur unwillig. Vielmehr ging sie vom unvermittelten Nebeneinander der harten politischen Realität und ihrer eitlen Zurschaustellung aus und erlag dabei modernen Unterscheidungen von Factum und Fictum, von Sein und Schein, von Basis und Überbau. Die Macht der Wörter überstrahlte die Suggestion der Bilder und die Imagination der Zeichen.

Unsere spätmittelalterlichen Texte fügten die Dinge dagegen noch viel deutlicher zusammen, begriffen Königswahl und Sitz- oder Prozessionsordnungen nicht als unterschiedliche Qualitäten von Politik, sondern als integrale Formen der Willensbildung und ihrer Präsentation. So goss man das Reich nicht nur in abstrakte Worte und Begriffe, sondern ließ es in Bildern und Vorstellungen erstehen. Man sah es, fühlte es, ahnte es: beim Sitzen, beim Laufen und beim Dienen. ${ }^{8}$ Dieser Kunst der Inszenierung als performativer Ritualisierung ${ }^{9}$ gilt in fünf Schritten unser Interesse.

\section{Zweierlei Bühnen der Macht}

Der Titel dieses Beitrags entstammt nicht erst dem ,performative turn' der Kulturwissenschaften im ausgehenden 20 . Jahrhundert. ${ }^{10}$ Schon die mittelalterlichen Quellen bauten sich ihre Bühnen der Macht auf Brettern, die das Reich bedeuteten. Im Kapitel 29 regelte die Goldene Bulle die Entlohnung der Amtleute beim Lehns-

Vgl. dazu den Beitrag von Michael BORGOLTE in diesem Band.

Zeremoniell und Raum, hg. von Werner PaRAviciNi (Residenzenforschung 6, 1997); Christoph WULF, Der performative Körper: Sprache - Macht - Handlung, in: Quel Corps? Eine Frage der Repräsentation, hg. von Hans BELTING / Dietmar KAMPER / Martin SCHULZ (2002) S. 207-218; Zwischen Gotteshaus und Taverne. Öffentliche Räume in Spätmittelalter und Früher Neuzeit, hg. von Susanne RAU / Gerd ScHwERHOFF (Norm und Struktur 21, 2004).

9 Stanley J. TAmBiAh, Eine performative Theorie des Rituals, in: Performanz. Zwischen Sprachphilosophie und Kulturwissenschaften, hg. von Uwe WIRTH (suhrkamp taschenbuch wissenschaft 1575, 2002) S. 210-242.

10 Geschichtswissenschaft und „Performative Turn“. Ritual, Inszenierung und Performanz vom Mittelalter bis zur Neuzeit, hg. von Jürgen MARTSCHUKAT / Steffen PATZOLD (Norm und Struktur 19, 2003); Gerrit Jasper SCHENK, Zeremoniell und Politik. Herrschereinzüge im spätmittelalterlichen Reich (RI Beih. 21, 2003). 
empfang der Fürsten vom Kaiser oder römischen König: „Nachdem all das ausgeführt ist, was auf einem kaiserlichen oder königlichen Hoftag jeweils auszurichten ist, soll der Hofmeister (magister curie) das ganze Gerüst oder die Holzaufbauten des kaiserlichen oder königlichen Sitzes (totum edificium sive ligneus apparatus imperialis sive regie sessionis) für sich erhalten, wo der Kaiser oder römische König mit den Kurfürsten zur Durchführung feierlicher Hoftage oder zur Vergabe von Lehen an Fürsten, wie oben ausgeführt, gesessen hat. “ll

Für ihr öffentliches Miteinander ließen sich Kaiser und Kurfürsten also aufwendige Bühnen zimmern. Seit 1348 sind Lehnsvergaben durch den König auf solchen Gerüsten bekannt. Die kostbaren Gewänder, die symbolischen Handlungen, das huldvolle Gewähren wie das demütige Knien - all diese personalen Bindekräfte der mittelalterlichen Gesellschaft sollten richtig gesehen werden. Der sitzende König mit offenen Händen und der kniende Vasall mit gefalteten Händen zeigten seit dem 13. Jahrhundert in immer ausgefeilteren Formen das Gefüge des Reichs vor aller Öffentlichkeit. ${ }^{12}$ Beim Metzer Hoftag zu Weihnachten 1356, wo der zweite Teil der Goldenen Bulle verkündet wurde, errichtete man ein Podest für etwa 200 Personen. $^{13}$

Ein europäisches Forum bot dann das Konstanzer Konzil. Seine politische Öffentlichkeit gerann in den Miniaturen der Konzilschronik Ulrich Richentals. Zur feierlichen Belehnung des Hohenzollern Friedrich mit der Mark Brandenburg ließ König Sigmund 1417 auf dem Marktplatz ein hohes, überdachtes Podest für etwa 30 Personen zimmern. Es war mit goldenen Tüchern ausgeschlagen, sodass es für den Betrachter geradezu von Gold brannte (es brunn von gold). ${ }^{14}$ König und Kurfürsten schritten aus einem Fenster direkt zu ihren Plätzen, während der neue Kurfürst von Brandenburg für alle sichtbar erst mühsam die Treppe emporsteigen musste. Solche Differenzierungen erhielten sich im monarchischen Zeremoniell bis ins 20. Jahr-

1 MGH Const. 11 S. 628,11-15. Zur Positionierung dieser Bestimmung (von der Übersetzung WEINRICHs an den Schluss von Kap. 30 geordnet: Quellen zur Verfassungsgeschichte (wie Anm. 2) S. 393) vgl. Bernd-Ulrich HERGEMÖLLER, Der Abschluß der „Goldenen Bulle“ zu Metz 1356/57, in: Studia Luxemburgensia. FS Heinz Stoob zum 70. Geburtstag, hg. von Friedrich Bernward FaHLBuSCH / Peter JoHANEK (Studien zu den Luxemburgern und ihrer Zeit 3, 1989) S. 123-232, hier S. $221 \mathrm{f}$.

12 Karl-Heinz SPIEB, Kommunikationsformen im Hochadel und am Königshof im Spätmittelalter, in: Formen und Funktionen öffentlicher Kommunikation im Mittelalter, hg. von Gerd AlthOFF (VuF 51, 2001) S. 261-290, vor allem S. 277-290.

13 Julius BRUCKAUF, Fahnlehn und Fahnenbelehnung im alten deutschen Reiche (Leipziger historische Abh. 3, 1907) S. 62 (ohne mittelalterlichen Beleg).

14 Ulrich von Richental, Chronik des Constanzer Concils 1414 bis 1418 , hg. von Michael Richard BUCK (1882) S. 104. 
hundert. Die Aufführung von König und Kurfürsten auf Bühnen gehörte im 15. Jahrhundert längst zum festen Repertoire des Imperiums. Im Kreis seiner Kurfürsten kam dem Kaiser ein erhöhter Sessel zu: Vorrang in der Gleichrangigkeit, Spiegel eines Reichs mit Haupt und Gliedern, mit Dach und Säulen.

Eine andere Bühne betrat der französische König bei seiner Krönung und Salbung im Reimser Weihezeremoniell. Auch hier wurde die Monarchie im Bund mit den Großen Frankreichs, den ,pairs de France' inszeniert, wenn auch in anderen, sakralen Bezügen. Das reich illuminierte Buch von der Krönung Karls V. im Jahr 1364 zeigt, wie zwölf Pairs gemeinsam die Krone stützten und damit ihren Konsens demonstrierten. ${ }^{15}$ Dann geleiteten sie in wohlbedachter Reihenfolge den König über einige Stufen auf eine Bühne. ${ }^{16}$ Die Krönungsordnung erläuterte die Zubereitung dieser Bühne, ihre Auskleidung mit Seide und die Aufstellung eines rundum sichtbaren Throns.

Das symbolische Verständnis beschrieb Jean Golein, der Beichtvater der Königin, im ,Traité du sacre', vom König 1374 eigenhändig seiner Bibliothek einverleibt (heute Paris, BNF, ms. fr. 437): Die Zwölfzahl der Pairs ergebe sich aus biblischem Vorbild. Alle zwölf müssten mit dem König und anderen auf der Bühne, dem eschaufaut (Schafott), Platz finden. Die räumliche Erhöhung symbolisiere die Erhebung des Königs im Sacre, der von der Bühne die Großen wie die Kleinen gleichermaßen sehe und ihnen Gerechtigkeit ohne Ansehen der Person gewähre. Die Bühne sei zum Himmel erhoben und von der Erde entfernt, auf dass der Herrscher und seine Pairs als Verkörperung des Reichs zwischen Gott und ihren Getreuen schwebten. Zudem zeige die Bühne, dass der König von Frankreich auf Erden niemanden über sich anerkenne. ${ }^{17}$ Die Krönungsordnung verband die Präsentation auf erhöhter Bühne mit erneuter Thronsetzung, dem Kuss des Reimser Erzbischofs unter Akklamation des Vivat Rex in Eternum und dem wiederholten Handanlegen der Pairs an die Krone des Königs. ${ }^{18}$ Auch die Erbmonarchie verschränkte also die Erhöhung des Herrschers und den Konsens der Getreuen.

Den symbolischen Übergang der Herrschaftsinsignien sowie die körperliche Verbindung in Berührung wie Kuss erklärte erneut Jean Golein in seinem Traktat. Der Erzbischof setze dem König die Krone auf, damit alle Pairs, Prälaten wie Ritter (tous

15 Carra Ferguson O'MEARA, Monarchy and Consent. The Coronation Book of Charles V of France. British Library MS Cotton Tiberius B. VIII (2001) Taf. 24 (fol. 59v).

16 Ebd. Taf. 25 (fol. 63r).

17 Benutzte Edition: Richard A. JACKSON, The Traité du sacre of Jean Golein, Proceedings of the American Philosophical Society 113 (1969) S. 305-324, Edition S. 308-324, hier S. $310 \mathrm{f}$.

18 O’MeARA, Monarchy (wie Anm. 15) Taf. 26 (fol. 64r). 


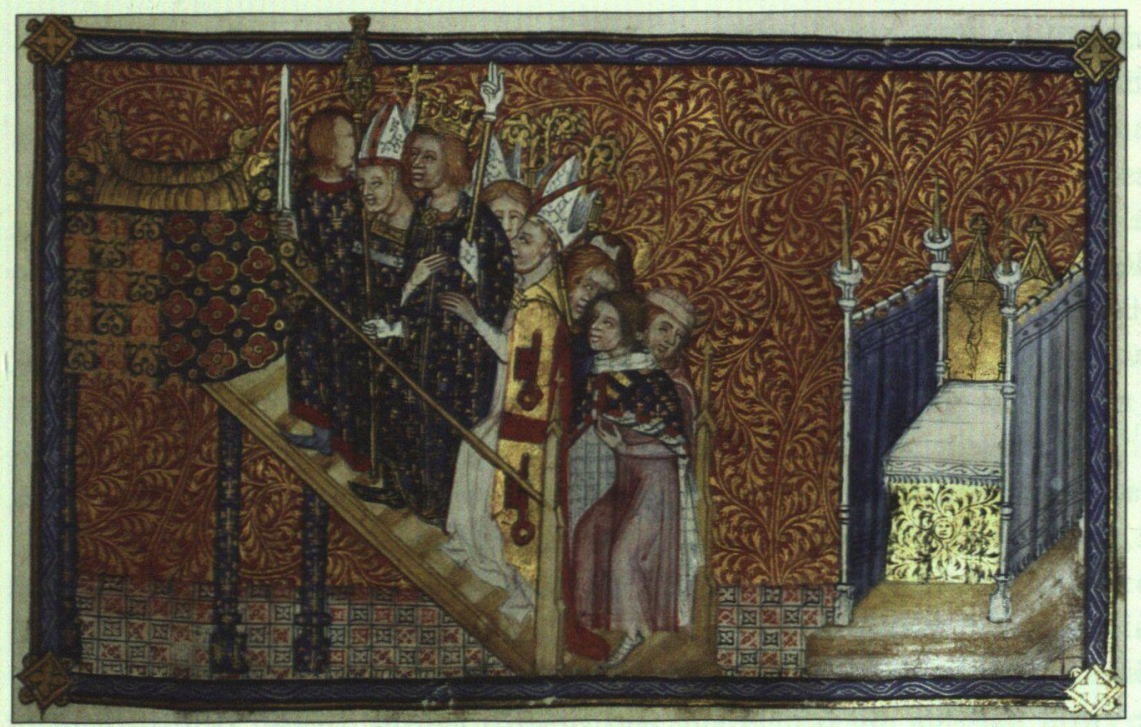

Abbildung 1

König Karl V. und die Akklamatoren im Aufzug zur Tribüne in der Kathedrale von Reims. London, BL, MS Cotton Tiberius B. VIII, fol. 63r (,Livre du sacre', 1365)

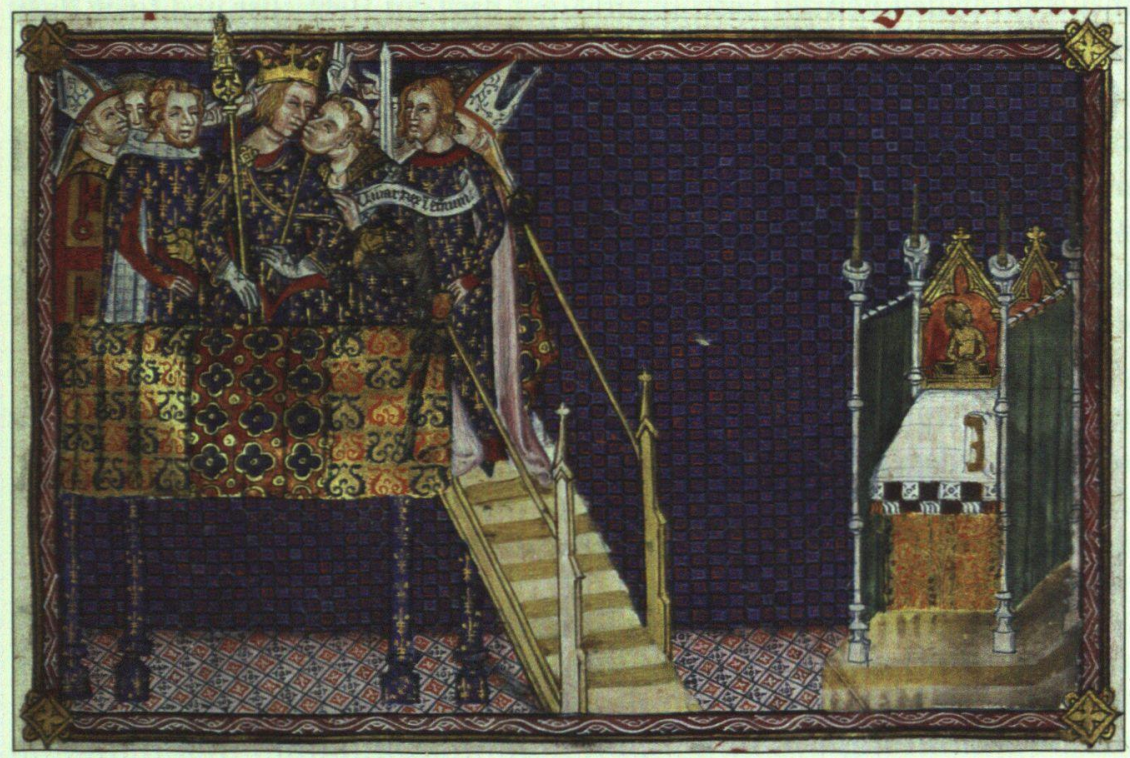

Abbildung 2

König Karl V. und die Akklamatoren auf der Tribüne in der Kathedrale von Reims.

London, BL, MS Cotton Tiberius B. VIII, fol. 64r (,Livre du sacre', 1365) 
les pers tant prelaz comme chevaliers), ihre Hände an die Insignie anlegten und damit ihre Dienste öffentlich vollführten. Der König säße dabei auf einem allgemein sichtbaren erhöhten Stuhl (chaere haute). Karl V. fügte der Handschrift selbst hinzu: „und ist dort inthronisiert" (et la est entronise). Hier spendeten der Erzbischof sowie die anderen geistlichen und weltlichen Pairs den Kuss, um damit Lehnsabhängigkeit (hommage) und Verbundenheit (union paisible et amiable) auszudrücken. ${ }^{19}$ Jean Golein beschrieb im französischen Krönungszeremoniell eine Sitzordnung der weltlichen und geistlichen Pairs um den König, die sich signifikant vom Modell der Goldenen Bulle von 1356 unterschied. Auch in Frankreich saßen die Pairs beim Weihezeremoniell in einer festen Ordnung (en leurs ordres) um den König, bis die Königin gesalbt war: die Laien zur Rechten, die Prälaten zur Linken. Im Vergleich von Imperium und Regnum waren bei geistlichen wie weltlichen Großen rechts und links in charakteristischer Weise vertauscht. Den ersten Platz der Prälaten zur Linken nahm der Erzbischof von Reims ein, danach der Bischof von Laon. ${ }^{20}$ Leider verzichtete Jean Golein in seinem Traktat auf die Platzierung der weiteren Pairs.

Bühnen auf kaiserlichen Hoftagen oder bei französischen Königsweihen fügten Herrscher und Fürsten also in öffentlicher Schau zusammen. Hier wurde nicht bloß abgebildet, was abstrakt in den Köpfen vorhanden war. Vielmehr entstand das Reich in seiner Inszenierung wie in den Imaginationen seiner Betrachter. Die kulturwissenschaftliche Forschung unterstrich das in neuerer Zeit zwar immer wieder, versäumte aber weitgehend den Brückenschlag zur Repräsentationstheorie des Spätmittelalters. Thomas von Aquin lehrte, dass die Darstellung der Ordnung das Gemeinwesen abbilde: Politeuma civitatis, id est positio ordinis in civitate, tota consistit in eo, qui dominatur civitati; et talis impositio ordinis est ipsa politia. ${ }^{21}$ Die Korporationslehre setzte im 14. Jahrhundert den Willen von Repräsentanten mit dem Willen der Gemeinschaft in eins. ${ }^{22}$ Johannes von Segovia unterschied in seiner Reichstagsrede von

JACKSON, Jean Golein (wie Anm. 17) S. 317.

20 Ebd. S. 318.

21 Thomas von Aquin, Sententia libri politicorum III 5, in: Sancti Thomae Aquinatis doctoris angelici Opera omnia iussu impensaque Leonis XIII. P. M. edita 48 (1971) S. A 201.

22 Vgl. Hasso HofMANN, Repräsentation. Studien zur Wort- und Begriffsgeschichte von der Antike bis ins 19. Jahrhundert (Schriften zur Verfassungsgeschichte 22, ${ }^{4} 2003$ ). Zur multiperspektivischen Verwendung von Repräsentation vgl. nur die drei völlig unterschiedlichen Lexikonartikel von Adalbert PODLECH, Repräsentation, in: Geschichtliche Grundbegriffe 5 (1984) S. 509-547 (zum Mittelalter S. 509-514); I. REITER, Repräsentation, in: HRG 4 (1990) Sp. 904 911; Horst WENZEL, Repräsentation, in: Reallexikon der deutschen Literaturwissenschaft 3 (2003) S. 268-271. Vgl. weiter: Der Begriff der Repraesentatio im Mittelalter, hg. von Albert ZIMMERMANN (Miscellanea Mediaevalia 8, 
1441 vier Formen der Repräsentation: Ähnlichkeit, Natur, Macht und Identität. Im vierten Typ, der Identitätsrepräsentation, bilde sich die Bürgergemeinde im Rat ab. ${ }^{23}$ Wenn man der neueren kulturalistischen Repräsentationsforschung vorwerfen könnte, sie habe diese Debatte unter Theologen und Kanonisten nicht angemessen rezipiert, so wird man ebenso einräumen, dass traditionelle Arbeiten zum politischen Denken der Kraft von Imaginationen und Inszenierungen skeptisch gegenüberstanden. Aus der Integration beider Denkmuster könnten neue Deutungsansätze erwachsen.

Auch die Macht der Vorstellungen ist keineswegs ein neues Thema. Um 1500 widmete Gianfrancesco Pico della Mirandola dem römischen König Maximilian I., einem Meister der Herrschaftsinszenierung, den Traktat De imaginatione. Der humanistische Autor beschrieb die Vorstellung (imaginatio), an der Grenze zwischen Intellekt und Sinneswahrnehmung; ihr Platz ist genau zwischen diesen beiden: Sie folgt auf die Sinneswahrnehmung, aus deren Aktualität sie entspringt, und geht der Tätigkeit des Intellekts voraus. Mit der Sinneswahrnehmung stimmt sie insofern überein, als sie - genau wie diese auch - Einzelnes, Körperliches und Gegenwärtiges aufnimmt; sie geht aber über die Sinneswahrnehmung hinaus, insofern sie ohne äußeren Anlaß Bilder produziert, die nicht nur Gegenwärtiges, sondern auch Vergangenes und Zukünftiges, ja sogar etwas, das von der Natur nicht geschaffen werden kann, zum Inhalt haben. Weiterhin stimmt sie mit der Sinneswahrnehmung überein, daß ihre Objekte sinnliche Abbilder sind. Insofern sie aber das von der Sinneswahrnehmung hinterlassene Material an Eindrücken noch nach dem Aufhören des Wahr-

1971); Roger CHARTIER, Le monde comme représentation, Annales 44 (1989) S. 1505 1520; Jürgen HABERMAS, Strukturwandel der Öffentlichkeit. Untersuchungen zu einer Kategorie der bürgerlichen Gesellschaft (suhrkamp taschenbuch wissenschaft 891, 1990); Carlo GinZBURG, Repräsentation - das Wort, die Vorstellung, der Gegenstand, Freibeuter 53 (1992) S. 2-23; Die Repräsentation der Gruppen. Texte - Bilder - Objekte, hg. von Otto Gerhard OEXLE / Andrea von HÜlSEN-ESCH (VMPIG 141, 1998); Quel Corps? (wie Anm. 8).

RTA 15 S. 648-759 Nr. 349, hier S. 681: Ceterum cum representacio sit quadruplex (similitudinis, quomodo in nummo aut in pariete imago regis impressa eum representat, nature item, qua filius representat patrem, potestatis quoque, sicut procurator dominum constituentem eum, idemptitatis eciam, ut consulatus representat civitatem eodem utens nomine et potestate). Eine ausführlichere Fassung seines Repräsentationskonzepts legte Johannes von Segovia, Liber de magna auctoritate episcoporum in concilio generali, hg. von Rolf DE KEGEL (Spicilegium Friburgense 34, 1995), hier Buch 1, bes. S. 141 ff., vor; vgl. Wolfgang MAGER, Genossenschaft, Republikanismus und konsensgestütztes Ratsregiment. Zur Konzeptionalisierung der politischen Ordnung in der mittelalterlichen und frühneuzeitlichen deutschen Stadt, in: Aspekte der politischen Kommunikation im Europa des 16./17. Jahrhunderts. Politische Theologie - Res Publica-Verständnis - konsensgestützte Herrschaft, hg. von Luise SCHORN-SCHÜTTE (HZ Beih. 39, 2004) S. 13-122. 
nehmungsprozesses nach Belieben verknüpft und trennt, ist sie der Sinneswahrnehmung überlegen; denn das könnte die Sinneswahrnehmung niemals leisten. “24 Die Inszenierung des Reichs sollte man in der Kombination dieser später geschiedenen Perspektivierungen studieren. Dabei sind die spätmittelalterliche Stellvertretungs- oder Identitätsrepräsentation der Kanonisten und die Bilder- und Imaginationslehre der Humanisten miteinander zu verknüpfen.

\section{Der rechte und der linke Sitz des Fürsten}

Programmatisch griff die Goldene Bulle das Wissen von der Herrschaftsordnung auf und unterstrich die heilsgeschichtliche Sonderstellung des Heiligen Römischen Reichs. Karl IV. definierte in dreifacher Weise die Ziele der Ordnungsstiftung, nämlich die „Förderung der Einigkeit unter den Kurfürsten“, die „Herbeiführung einer einstimmigen Wahl“ und die „Behebung der vorgenannten abscheulichen Spaltung“ 25 Grundlage dieser konsensualen Herrschaft war die Überzeugung, dass die Kurfürsten nicht nur Säulen des Reichs, sondern Teil des kaiserlichen Körpers seien. ${ }^{26}$ Zur Konfliktvermeidung fixierte die Goldene Bulle Regeln: für die Sitzordnung der Kurfürsten, für die Reihenfolge ihrer Stimmabgabe, für den Vorrang der Kurfürsten vor allen anderen, für die Prozessionsordnung der Erzbischöfe wie aller Kurfürsten, für das Erscheinen der Kurfürsten auf feierlichen Hoftagen, für ihre Dienste und Hofämter und für die Ordnung der kaiserlichen Tafel.

In der personalen Gesellschaft des Spätmittelalters bedeutete die Zurücksetzung einer Person im Raum einen unerträglichen Ehrverlust. Die historische Forschung tat sich lange schwer, die Pergament verschwendenden Passagen zur Sitzordnung der Kurfürsten und zu Prozessionsordnungen des Reichs angemessen zu würdigen. Symptomatisch ist ein 1968 formuliertes Urteil: „Ausdrücklich zur Vermeidung künftiger

24 Gianfrancesco Pico della Mirandola, Über die Vorstellung. De imaginatione, hg. von Eckhard KeSSLER (Humanistische Bibl. II 13, ${ }^{3} 1997$ ) S. 98 f. (Kap. 3).

MGH Const. 11 S. 564,4 f. Zur Eröffnung der Goldenen Bulle Bernd-Ulrich HERGEMÖLLER, Cogor adversum te. Drei Studien zum literarisch-theologischen Profil Karls IV. und seiner Kanzlei (Studien zu den Luxemburgern und ihrer Zeit 7, 1999) S. 126-220; vgl. ferner Hans HatTEnHAuer, Bibel und Recht in der Goldenen Bulle von 1356, in: FS Louis Carlen zum 60. Geburtstag, hg. von Louis C. MORSAK / Markus EsCHER (1989) S. 627637.

MGH Const. 11 S. 616,14 f.: „Denn sie sind Teil unseres Körpers“ (nam et ipsi pars corporis nostri sunt). Der Text folgt hier dem Codex Iustinianus IX 8,5. Zum crimen laesae maiestatis vgl. Ernst SCHUBERT, König und Reich. Studien zur spätmittelalterlichen deutschen Verfassungsgeschichte (VMP1G 63, 1979) S. 139-146. 
Streitigkeiten (III, XXI) werden Sitz-, Stimm- und Prozessionsordnung sowie Verteilung der Erzämter unter den Kurfürsten im Kaiserlichen Rechtsbuch endgültig geregelt. Man mag dergleichen für lächerlich erachten; rein mittelalterlich sind diese Probleme indessen nicht; selbst in unserer Zeit wird die Aufstellung führender Persönlichkeiten bei bestimmten öffentlichen Feiern auch von ernsthaften Leuten gelegentlich politisch gedeutet. ${ }^{\text {“27 }}$ Die ernsthaften Leute vermehren sich derzeit. Sie betrachten die Positionierung des Individuums im Raumgefüge als Zeichen seiner Bedeutung. Darum sollen die Regelungen der Goldenen Bulle zum Sitzen, zum Laufen und zum Dienen als Konfigurationen des Reichs im Handlungsverband seiner Träger vorgestellt werden.

Weltliche Fürsten akzeptierten im Mittelalter nur den Vorrang der Geistlichkeit als Mittler zum Heil. Darum traten die drei Erzbischöfe von Mainz, Köln und Trier unstrittig vor die vier weltlichen Königswähler. Doch innerhalb der beiden Gruppen wurden über die Jahrhunderte heftige Rangkonflikte ausgetragen, die sich aus historisch begründeten Ansprüchen und mittelalterlichen Ehrkonzepten speisten. ${ }^{28}$ Die Festlegung der Sitzordnung (sessio) der drei Erzbischöfe in Kapitel 3 zielte darum auf den einmütigen Willen der Königswähler, denn dieser förderte den Schmuck und Ruhm des hochheiligen römischen Reichs (decor et gloria sacrosancti Romani imperii), die kaiserliche Ehre (honor cesareus) und den willkommenen Vorteil des Gemeinwesens (reipublice grata compendia). Je mehr die Kurfürsten „durch die weitherzige Güte gegenseitiger Gewohnheit verbunden sind, desto reicher ergießt sich der Segen des Friedens und der Ruhe heilbringend über das christliche Volk“. ${ }^{29}$ Frieden und Ruhe (pax et tranquillitas) unter den Erzbischöfen von Mainz, Köln und Trier, bisher durch Hader und Argwohn über Vorrang und Würde ihrer Sitz-

27 Die güldin bulle und künigclich reformacion, Straßburg 1485. Der erste illustrierte Druck des Kaiserlichen Rechtbuches Karls IV. aus dem Jahre 1356. Faksimiledruck mit einer Einl. von Armin WOLF, 2 Bde. (Mittelalterliche Gesetzbücher Europäischer Länder in Faksimiledrucken 1, 1968), hier Kommentarbd. S. 15 f. Wiederholung in Armin WoLF, Das „Kaiserliche Rechtbuch“ Karls IV. (sogenannte Goldene Bulle), Ius commune 2 (1969) S. 1-32, hier S. 14.

28 Zu Ehrkonzepten: Verletzte Ehre. Ehrkonflikte in Gesellschaften des Mittelalters und der Frühen Neuzeit, hg. von Klaus SchreINER / Gerd SCHWERHOFf (Norm und Struktur 5, 1995); Ehrkonzepte in der Frühen Neuzeit. Identitäten und Abgrenzungen, hg. von Sibylle BACKMANN / Hans-Jörg KÜNAST / Beverly Ann TLUSTY / Sabine UlLMANN (Colloquia Augustana 8, 1998); Matthias LENTZ, Konflikt, Ehre, Ordnung. Untersuchungen zu den Schmähbriefen und Schandbildern des späten Mittelalters und der frühen Neuzeit (ca. 1350 bis 1600). Mit einem illustrierten Katalog der Überlieferung (Veröff. der Historischen Kommission für Niedersachsen und Bremen 217, 2004).

24 MGH Const. 11 S. 578,25-30. 


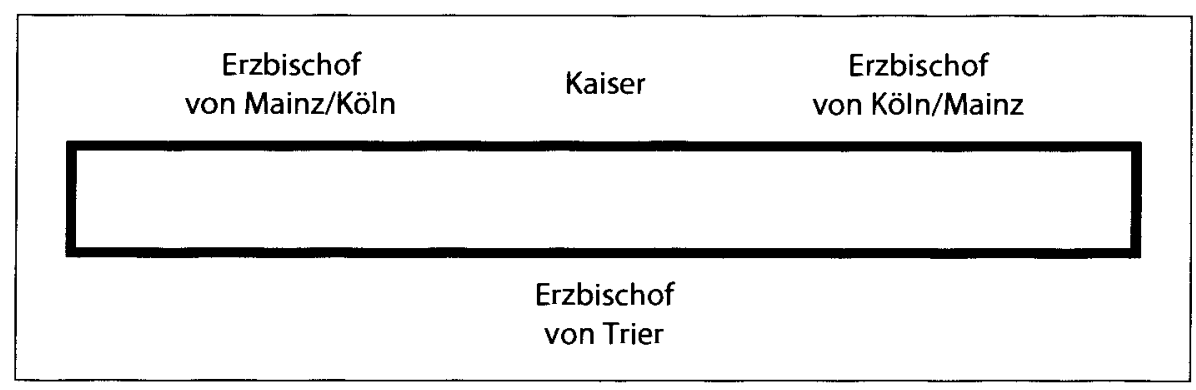

Abbildung 3

Die Sitzordnung der Goldenen Bulle

ordnung (prioritas seu dignitas sessionum suarum) bedroht, wurden nun für die Zukunft gesichert. Ziel war der ruhige Zustand des Herzens und der Sinne, das Nachdenken ,über die Belange des heiligen Reichs in einträchtiger Liebe und im Eifer kraftvoller Zuneigung“, also Konfliktbeilegung durch rationalisierte Übereinkunft.

Am begehrtesten war der rechte Platz neben dem Kaiser. ${ }^{30}$ Um ihn war es seit 1273 zu heftigen Kämpfen zwischen dem Mainzer und dem Kölner Erzbischof gekommen. Beim Krönungsmahl König Rudolfs 1273 in Aachen musste der Mainzer dem Kölner den Vorrang einräumen. ${ }^{31}$ Doch beim neuerlichen Ringen auf dem ersten Hoftag Albrechts I. 1298 in Nürnberg setzte sich der Mainzer durch, was seinen Rivalen zum Verlassen der Versammlung nötigte. ${ }^{32}$

Allmählich zeichnete sich der Ehrenvorrang des Metropoliten in seiner eigenen Kirchenprovinz ab. Das schrieb man in die Goldene Bulle: Im deutschen Reich gehörte der rechte Platz im Prinzip dem Erzbischof von Mainz. Nur in der Erzdiözese Köln sowie in Italien und Gallien fiel er dem Kölner Erzbischof zu, da ihm eine Minderung in seinem Sprengel nicht zumutbar war. Dem Erzbischof von Trier mach-

30 Reinhard ELzE, Rechts und Links. Bemerkungen zu einem banalen Problem, in: Das Andere Wahrnehmen. Beiträge zur europäischen Geschichte. August Nitschke zum 65. Geburtstag gewidmet, hg. von Martin KINTZINGER / Wolfgang STÜNER / Johannes ZAHLTEN (1991) S. 75-82; Hans-Werner GoETZ, Der ,rechte“ Sitz. Die Symbolik von Rang und Herrschaft im Hohen Mittelalter im Spiegel der Sitzordnung, in: Symbole des Alltags Alltag der Symbole. FS Harry Kühnel zum 65. Geburtstag, hg. von Gertrud BLASCHITZ / Helmut HUNDSBICHLER / Gerhard JARITZ / Elisabeth VAVRA (1992) S. 11-47.

31 MGH Const. 3 S. 15 f. Nr. 12 f.; Sächsische Weltchronik, hg. von Ludwig WEILAND (MGH DC 2, 1877) S. 286 (Sächsische Fortsetzung).

32 Ottokars Österreichische Reimchronik, hg. von Joseph SEEMÜLLER, 2 Bde. (MGH DC 5 , 1890-1893) S. 969 V. 73401 ff. 
te man den Vorzug seiner Amtskollegen erträglich, indem er grundsätzlich dem Kaiser gegenüber saß. Das galt für die lebenden Erzbischöfe wie ihre Nachfolger bei „allen öffentlichen kaiserlichen Handlungen, also Gerichtssitzungen, Lehnsverleihungen und Festmählern und auch bei Beratungen wie allen anderen Handlungen". ${ }^{33}$

Dieses Grundkonzept regelte auch die kaiserliche Tischordnung für feierliche Hoftage (Kap. 28). Sie berücksichtigte sogar, wenn auch abgestuft, die Kaiserin, die in einem Wahlreich unwichtiger als jede europäische Königin in den Erbmonarchien war. Der Kaiser oder römische König und seine Gemahlin speisten jeweils für sich an zwei Tischen, die deutlich über den Tischen der Kurfürsten erhaben im Raum positioniert wurden. Die kaiserliche mensa erhob sich mindestens sechs Fuß, die seiner Gemahlin seitwärts wenigstens drei Fuß über den Tischen der Kurfürsten. Die Hofdienste aller Kurfürsten mussten von allen stehend abgewartet werden. Erst danach setzte man sich im gleichen Moment zu Tisch. Die sitzende Gegenwart beim Dienst eines anderen Kurfürsten hätte unerträgliche Überlegenheit geschaffen. ${ }^{34}$ Erzählende Quellen geben uns wichtige Hinweise für die rituelle Umsetzung solch normativer Bestimmungen. Bei der Publikation der Goldenen Bulle zu Weihnachten 1356 in Metz überführten Kaiser, Kurfürsten und Fürsten das Verabredete in zeremonielle Praxis. Chronisten beschrieben die fortgesetzte prachtvolle Repräsentation von Kaiser und Reich in seiner heilsgeschichtlichen Verankerung. Zur Weihnachtsmesse las Kaiser Karl IV. das Lukasevangelium (Kap. 2) vom Gebot des Kaisers Augustus, dass alle Welt geschätzt würde. Damit betonte er seit 1347 in wiederholten Ritualakten den zeitlichen Vorrang des Kaisertums vor der Entstehung der christlichen Kirche. ${ }^{35}$

33 MGH Const. 11 S. 580,10-12.

34 Vgl. Johannes KuNISCH, Formen symbolischen Handelns in der Goldenen Bulle von 1356, in: Vormoderne politische Verfahren, hg. von Barbara STOLLBERG-RILINGER (ZHF Beih. 25, 2001) S. 263-280; außerdem: Essen und Trinken in Mittelalter und Neuzeit, hg. von Irmgard Bitsch / Trude EHLERT / Xenja von ERTZDORFF (1987); Uta Löwenstein, Voraussetzungen und Grundlagen von Tafelzeremoniell und Zeremonientafel, in: Zeremoniell als höfische Ästhetik in Spätmittelalter und Früher Neuzeit, hg. von Jörg Jochen BERNS / Thomas RAHN (Frühe Neuzeit 25, 1995) S. 266-279; Die öffentliche Tafel. Tafelzeremoniell in Europa 1300-1900, hg. von Hans OTTOMEYER / Michaela VöLKEL (2002). Zur Wirkung der Goldenen Bulle auf frühneuzeitliche Krönungen Bernd Herbert WANGER, Kaiserwahl und Krönung im Frankfurt des 17. Jahrhunderts. Darstellung anhand der zeitgenössischen Bild- und Schriftquellen unter besonderer Berücksichtigung der Erhebung des Jahres 1612 (Studien zur Frankfurter Geschichte 34, 1994) S. 125-130.

35 Vgl. z. B. den Bericht vom Weihnachtsgottesdienst 1355 in Nürnberg mit der Evangelienlesung Karls IV. bei Heinrich von Diessenhofen: Et ipse imperator astantibus principibus 
Es schlossen sich die erste Messe eines Kardinallegaten und das vom Kölner Erzbischof zelebrierte feierliche Hochamt an. Dann geleiteten alle Erzbischöfe, Bischöfe, Prälaten und weltlichen Fürsten den Kaiser und die Kaiserin im vollen imperialen Ornat feierlich zum Speisehaus, mitten in der Stadt auf einem Platz bereitet und wunderschön geschmückt, wo Tafeln für die Eingeladenen aufgestellt waren. Hier führten die Hofamtsträger des Reichs vor dem erhöht speisenden Kaiser ihre Dienste auf, die Erzbischöfe mit den Siegeln, dann der Herzog von Sachsen als Erzmarschall, der Markgraf von Brandenburg als Erzkämmerer, der Pfalzgraf bei Rhein als Erztruchsess und schließlich Herzog Wenzel von Luxemburg und Brabant, der Bruder des Kaisers, als Stellvertreter des Königs von Böhmen als Erzschenk. Keiner konnte sich an ein solch prächtiges convivium erinnern. ${ }^{36}$ Am Schluss gab der Kaiser den verschiedenen Fürsten freigebig verschiedene wunderbare Geschenke, und ein jeder kehrte fröhlich nach Hause zurück: „Denn dieser Hoftag war feierlicher, als von irgendeinem Kaiser in langen vergangenen Zeiten geschrieben ist. ${ }^{37}$ Mit 32 Fürsten hielt der Kaiser Hof, ,und dort nahmen viele ihre Lehen vom Kaiser und dienten nach ihrer Ordnung. “38

et imperatrice coronata legit in matutino septimam lectionem gladio evaginato ut est moris; Heinricus de Diessenhofen und andere Geschichtsquellen Deutschlands im späteren Mittelalter, hg. aus dem Nachlasse Johann Friedrich BöHMERs von Alfons HUBER (Fontes rerum Germanicarum 4, 1868) S. 16-126, hier S. 101 f. Zur Sache Hermann HEIMPEL, Königliche Evangeliumslesung bei königlicher Krönung, in: Aus Kirche und Reich. Studien zu Theologie, Politik und Recht im Mittelalter. FS Friedrich Kempf, hg. von Hubert MORDEK (1983) S. 447-459; Hermann HEIMPEL, Königlicher Weihnachtsdienst im späteren Mittelalter, DA 39 (1983) S. 131-206; Martin KINTZINGER, Der weiße Reiter. Formen internationaler Politik im Spätmittelalter, FMASt 37 (2003) S. 315-353.

Chronicon Benessii de Weitmil (Kronika Beneše z Weitmile), hg. von Josef EMLER (FRB 4, 1884; ND 2004) S. 457-548, hier S. 526. Ein weiterer ausführlicher Bericht mit Nennung der hochadeligen Teilnehmer: Die Metzer Chronik des Jaique Dex (Jacques d'Esch) über die Kaiser und Könige aus dem Luxemburger Hause, hg. von Georg WoLfRAM (Quellen zur lothringischen Geschichte 4, 1906) S. 303-307 (Kap. 37).

Die Chronik des Mathias von Neuenburg, hg. von Adolf HofMEISTER (MGH SS rer. Germ. NS 4, 1924-1940) S. 486.

Heinricus de Diessenhofen (wie Anm. 35) S. 107. Weitere Zeugnisse zum Metzer Hoftag 1356/57 in RI 8 Nr. 2555a; Gabriele ANNAS, Hoftag - Gemeiner Tag - Reichstag. Studien zur strukturellen Entwicklung deutscher Reichsversammlungen des späten Mittelalters (1349-1471) 2: Verzeichnis deutscher Reichsversammlungen des späten Mittelalters (Schriftenreihe der Historischen Kommission bei der Bayerischen Akademie der Wissenschaften 68,2004$)$ S. 55-66. 
Der Metzer Hoftag brachte also nicht nur normative Bestimmungen zur Festkultur mittelalterlicher Hoftage hervor. Durch ihren Glanz und durch die wirkungsvolle Inszenierung des kaiserlichen Treffens mit dem Kardinallegaten wie dem französischen Thronfolger Karl (V.) zählte die Versammlung zu den Höhepunkten der imperialen Repräsentationskultur Karls IV. ${ }^{39}$

In der normativen Speisegemeinschaft der Goldenen Bulle (Kap. 28) formten sich Hierarchie und Gleichrangigkeit miteinander aus. 350 Jahre früher hatte Bischof Thietmar von Merseburg noch mit erkennbarer Verwunderung von Erneuerungen römischer Sitten durch Kaiser Otto III. (983-1002) erzählt: „So pflegte er ganz allein an einem halbkreisförmigen, erhöhten Tische zu tafeln." In der Kriegergemeinschaft des frühen 11. Jahrhunderts löste das noch größtes Erstaunen aus, sodass „Verschiedene verschieden darüber dachten" (diversi diverse sentiebant).$^{40}$ Die Bestimmungen der Goldenen Bulle erweisen, dass sich die Einsamkeit des Herrscherpaars im Tischzeremoniell mittlerweile durchgesetzt hatte. Die dichtere Quellenüberlieferung belegt für das Spätmittelalter mit seiner zunehmenden Internationalisierung ${ }^{41}$ europäischer Zusammenkünfte sowohl heftige Friktionen um den vornehmeren Platz ${ }^{42}$ als auch die zunehmende Bedeutung rechtzeitiger Aushandlung der Sitzordnung ${ }^{43}$ zur Konfliktvermeidung.

39 Peter MoRAw, Über den Hof Kaiser Karls IV., in: Deutscher Königshof, Hoftag und Reichstag im späteren Mittelalter, hg. von Peter MoRaw (VuF 48, 2002) S. 77-103.

40 Die Chronik des Bischofs Thietmar von Merseburg, hg. von Robert HoltzMANN (MGH SS rer. Germ. NS 9, 1935) S. 184,31-33 (Kap. IV 47).

$41 \mathrm{Zu}$ den spätmittelalterlichen Herrschertreffen vgl. Gerald SCHWEDLER, Herrschertreffen des Spätmittelalters. Formen, Rituale, Wirkungen (Mittelalter-Forschungen 21, 2008).

42 Johannes Helmrath, Rangstreite auf Generalkonzilien des 15. Jahrhunderts als Verfahren, in: Vormoderne politische Verfahren (wie Anm. 34) S. 139-173. Zum Verhältnis Kaiser Friedrichs III. und Herzog Karls des Kühnen von Burgund vgl. Petra EHM, Burgund und das Reich. Spätmittelalterliche Außenpolitik am Beispiel der Regierung Karls des Kühnen (1465-1477) (PHS 61, 2002); Klaus OschEMA, Freundschaft und Nähe im spätmittelalterlichen Burgund. Studien zum Spannungsfeld von Emotion und Institution (Norm und Struktur 26, 2006); Heribert MülLER, Théâtre de la préséance. Les ducs de Bourgogne face aux grandes assemblées dans le Saint-Empire (Conférences annuelles de l'Institut historique allemand 13, 2007).

43 Der Reichserbmarschall Wilhelm von Pappenheim ließ für den Wormser Reichstag von 1495 eine detaillierte Sitzordnung anfertigen: RTA Mittlere Reihe 5 S. 1172 f. Nr. 1598. 


\section{Der Aufzug des Reichs}

Das fein gesponnene Einigungswerk unter den drei Erzbischöfen wurde auf die Aufzüge von König und Kurfürsten übertragen. Wieder ging es um die Definition von Ordnung (ordinem diffinire). Dem Sitzkonzept (Kap. 3, 28) entsprachen die Ordnungen der Prozessionen und feierlichen Aufzüge (Kap. 21-22). Wenn bei einer Versammlung von Kaiser und Erzbischöfen die Herrscherinsignien vor dem Antlitz des Kaisers oder Königs getragen wurden, dann sollte der Trierer , in gerader Linie unmittelbar vor dem Kaiser oder König gehen, und zwischen ihnen sollen allein diejenigen gehen, welche die kaiserlichen oder königlichen Herrschaftszeichen tragen. ${ }^{\text {"44 }}$ Den rechten und den linken Platz auf dem Marsch nahmen nach der fixierten Ordnung ihrer Diözesen der Mainzer und der Kölner ein. Diesem Kernensemble konnte man schließlich noch die vier weltlichen Kurfürsten hinzufügen. Dafür schuf die Goldene Bulle eine neue Eindeutigkeit an der Spitze. Unmissverständlich präzisierten Kaiser und Kurfürsten den Vorrang des Böhmen vor dem Pfalzgrafen bei Rhein, dem Herzog von Sachsen und dem Markgrafen von Brandenburg. Der erste Platz falle dem König von Böhmen zu, ,da er ein gekrönter und gesalbter Fürst ist" (cum sit princeps coronatus et unctus). ${ }^{45}$

Damit entschied der Kaiser, der gleichzeitig Böhmenkönig war, einen mehr als hundert Jahre schwelenden Streit. ${ }^{46}$ Im 13. Jahrhundert hatte der Sachsenspiegel den Böhmenkönig noch aus der Reihe der Königswähler eliminiert, weil er kein Deutscher sei. ${ }^{47}$

Immerhin hob die Königskrone den Böhmen über die anderen Reichsfürsten hinaus. Auch wenn der böhmische König vom römischen König sein Reich empfing, warf das rituelle Miteinander zweier gekrönter Könige in mittelalterliche Über- und Unterordnung beträchtliche Rangprobleme auf. Die Sonderstellung des Böhmen als gekrönter und gesalbter König im Miteinander mit dem römischen König und Kaiser erfuhr unter Karl IV., der ja selbst die römische wie die böhmische Krone trug, be-

\footnotetext{
MGH Const. 11 S. 612,1-5 (Kap. 21).

Ebd. S. 580,25 f. (Kap. 4).

Zur Stellung des böhmischen Königs in der Reichsordnung vgl. Alexander BEGERT, Böhmen, die böhmische Kur und das Reich vom Hochmittelalter bis zum Ende des Alten Reiches. Studien zur Kurwürde und zur staatsrechtlichen Stellung Böhmens (Historische Studien 475, 2003).

Sachsenspiegel. Landrecht, hg. von Karl August ECKHARDT (MGH Fontes iuris NS 1/1, 1955) S. 243 (Kap. III 57 §): De scenke des rikes, de koning van Behemen, de ne hevet nenen kore, umme dat he nicht dudisch n'is.
}

47 
reits am 7. April 1348 eine präzise Ausgestaltung. ${ }^{48}$ Er bestätigte damals eine Urkunde König Albrechts I. Am 17. November 1298 hatte der Habsburger verkündet, dass die böhmischen Könige auf einem Hoftag des gekrönten römischen Königs ihre eigene Krone tragen dürften. Doch ein Hofamt unter der Krone war ihnen nicht zuzumuten. Den Dienst als Mundschenk müssten sie darum nicht bekrönt verrichten (non tamen in corona regia debent predicti reges Boemie predictis regi vel imperatori ministrare in officio pincernatus). König Wenzel II. hatte auf dem Nürnberger Hoftag vom 16. November 1298 gleichwohl das Erzschenkenamt unter der Krone ausgeübt. Also verfügte König Albrecht, dass dies nicht aufgrund eines Rechtsanspruchs (de iure), sondern aus reiner Zuneigung Wenzels zur Person des römischen Königs geschehen sei (sed ex mera dileccione, quam ad nostram gerit personam), woraus kein Anspruch (preiudicium) an die künftigen böhmischen Könige erwachsen dürfe. ${ }^{49}$ In dieser Traditionslinie, fußend auf der karolinischen Bestätigung von 1348, fiel dem gekrönten Böhmenkönig in der Goldenen Bulle der Vorrang unter den weltlichen Reichsfürsten zu.

Damit beendete Karl IV. die bisherige Sonderstellung des Pfalzgrafen bei Rhein. Rudolf von Habsburg und die Fürsten hatten 1274 im Kampf gegen König Ottokar von Böhmen den Pfalzgrafen bei Rhein zum Richter zwischen dem König und einem Fürsten werden lassen. Wiederholt übten die rheinischen Pfalzgrafen bei den nächsten Königswahlen ihre besondere Gestaltungskraft aus. ${ }^{50}$ Das Erinnerungsbild von der Königswahl Heinrichs VII. (1308-1313), des Großvaters Karls IV., im Codex Balduineus (nach 1330) zeigte den Pfalzgrafen bei Rhein in der Mitte der sieben Königswähler. ${ }^{51}$

48 Bestätigung Karls IV. von 1348 April 7: MGH Const. 8 S. 570 f. Nr. 562. Vgl. BEGERT, Böhmen (wie Anm. 46) S. 121-125, und den Beitrag von Lenka BoBKová in diesem Band.

49 MGH Const. 4 S. 31 f. Nr. 35.

50 Das Weistum König Rudolfs und der Reichsfürsten MGH Const. 3 S. 59-61 Nr. 72. Zum Vorrang der rheinischen Pfalzgrafen im 13./14. Jahrhundert vgl. Peter MORAW, Die kurfürstliche Politik der Pfalzgrafschaft im Spätmittelalter, vornehmlich im späten 14. und frühen 15. Jahrhundert, Jb. für westdeutsche LG 9 (1983) S. 75-97; Meinrad SCHAAB, Geschichte der Kurpfalz 1 ( $\left.{ }^{2} 1999\right)$; Mittelalter. Der Griff nach der Krone. Die Pfalzgrafschaft bei Rhein im Mittelalter (Schätze aus unseren Schlössern. Eine Reihe der staatlichen Schlösser und Gärten Baden-Württemberg 4, 2000); Volker RöDEL, Die Geburt der Kurpfalz, Mitt. des Historischen Vereins der Pfalz 100 (2002) S. 217-238.

51 Wolfgang SCHMID, Kaiser Heinrichs Romfahrt. Zur Inszenierung von Politik in einer Trierer Bilderhandschrift des 14. Jahrhunderts (Mittelrheinische Hefte 21, 2000) S. 135. 
Die Stellung der wittelsbachischen Dynastie wurde freilich durch das umstrittene König- und Kaisertum Ludwigs IV. (1314-1347) erschüttert. Gegen ihn setzte sich 1346/47 Karl IV. durch und spaltete alsbald die Einheit seiner einstigen wittelsbachischen Feinde. Nach den Bestimmungen des Hausvertrags von Pavia 1329 hätte die Wahlstimme des Pfalzgrafen bei Rhein zwischen den wittelsbachischen Linien in der Pfalz und in Bayern alternieren müssen. ${ }^{52}$ Aber Karl IV. zog den rheinischen Pfalzgrafen Rudolf II. (1329-1353) auf seine Seite und heiratete dessen Tochter Anna. Mit Rudolfs Nachfolger Ruprecht I. (1353-1390) vereinbarte der neue Kaiser am 27. Dezember 1355, wenige Tage vor der Verkündung des ersten Teils der Goldenen Bulle, die alleinige Kurwürde der pfälzischen Linie. ${ }^{53}$ Das ,Reichsrecht' des Kaisers brach im Selbstverständnis der pfälzischen Kurfürsten das ,Hausrecht' der Wittelsbacher. In der prekären Situation des Jahres 1356 konnte Pfalzgraf Ruprecht I. aber den zeremoniellen Vorrang unter den weltlichen Königswählern nicht mehr verteidigen. Diesen ersten Rang musste er seinem kaiserlichen Gönner überlassen, der in der Goldenen Bulle bleibend die Stellung der böhmischen Könige im zeremoniellen Gefüge des Reichs festschrieb. Damit war die Reihenfolge unter den weltlichen Kurfürsten entschieden.

Die Goldene Bulle setzte den ersten Platz des Böhmen wiederholt in Szene: Bei gemeinsamer Anwesenheit geistlicher und weltlicher Kurfürsten auf dem Hoftag (Kap. 4) durfte der Böhme gleich neben dem Erzbischof zur Rechten des Königs sitzen, vor dem rheinischen Pfalzgrafen. Zur Linken schlossen sich nach dem Erzbischof der Herzog von Sachsen und der Markgraf von Brandenburg an. Dem nicht eigens genannten (gegenübersitzenden) Trierer Erzbischof wuchs zum Ausgleich das Recht der ersten Stimmabgabe bei der Königswahl zu. Dort folgten ihm der Erzbischof von Köln, ,,dem Würde und Amt zukommen, dem römischen König die erste Königskrone aufzusetzen“, der König von Böhmen, „,er unter den Laienwählern auf Grund der Hoheit seiner Königswürde mit Recht den ersten Rang (primacia) einnimmt", der Pfalzgraf bei Rhein, der Herzog von Sachsen, der Markgraf von Brandenburg und schließlich der Erzbischof von Mainz als Verhandlungsführer mit der bei strittiger Abstimmung unter Umständen entscheidenden siebten Stimme. ${ }^{54}$

52 Wittelsbacher Hausverträge des späten Mittelalters. Die haus- und staatsrechtlichen Urkunden der Wittelsbacher von 1310,1329, 1392/93, 1410 und 1472, bearb. von Rudolf HeINRICH u. a., hg. von Hans RaLl (Schriftenreihe zur Bayerischen LG 71, 1987) S. 64 174, hier S. 93.

53 MGH Const. 11 S. 363 Nr. 649. Vgl. dort auch die Urkunden von 1354 und 1355 , Nr. 178 f., 184, 370.

54 Vgl. Ulrich STUTZ, Die Abstimmungsordnung der Goldenen Bulle, ZRGGermAbt 43 (1922) S. 217-266. 


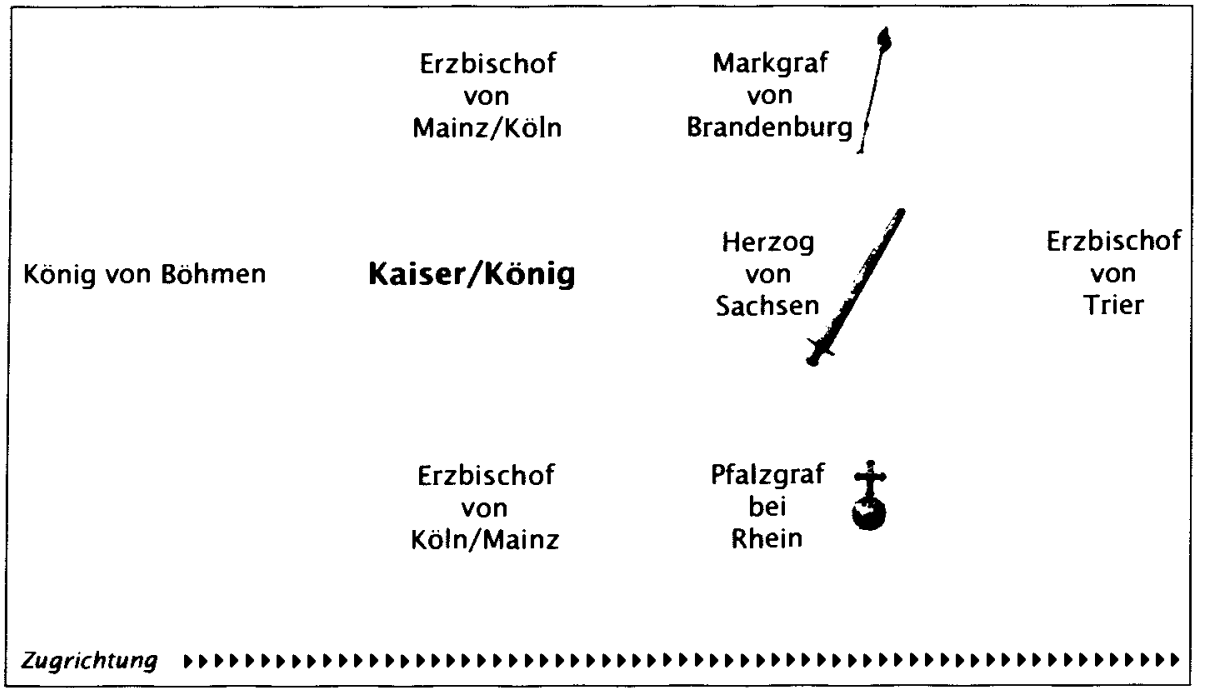

Abbildung 4

Die Prozessionsordnung der Goldenen Bulle

Zur Sitzordnung der sieben trat eine erweiterte Prozessionsordnung (Kap. 22). Sie entfaltete das fein gesponnene Ranggefüge. Besondere Aufmerksamkeit erfuhr die Mitführung der Herrschaftsinsignien durch den Pfalzgrafen bei Rhein, den Herzog von Sachsen und den Markgrafen von Brandenburg vor dem bekrönten König. Diese öffentliche Schau präsentierte den handgreiflichen Anteil der Kurfürsten am Reich und seinen Insignien. Neben der bloßen Prozession mit den Erzbischöfen fügte das Kapitel 22 auf halber Distanz zwischen dem Herrscher und dem voranschreitenden Trierer Erzbischof eine zusätzliche Achse von drei weltlichen Kurfürsten in den Bewegungsraum des Reichs, mit dem Herzog von Sachsen in der Mitte, dem Pfalzgrafen bei Rhein zur Rechten, dem Markgrafen von Brandenburg zur Linken. Diese drei führten die wichtigsten Insignien des Kaisertums mit sich, der Herzog von Sachsen das Schwert als Zeichen von Herrschaft und Gerichtsgewalt, ${ }^{55}$ der Pfalzgraf

55 Zu den Insignienträgern Jürgen PETERSOHN, Über monarchische Insignien und ihre Funktion im mittelalterlichen Reich, HZ 266 (1998) S. 47-96, hier S. 82 f. Zur Bedeutung der mittelalterlichen Herrschaftszeichen Percy Emst SCHRAMM, Herrschaftszeichen und Staatssymbolik. Beiträge zu ihrer Geschichte vom dritten bis zum sechzehnten Jahrhundert, 3 Bde. (MGH Schriften 13, 1954-1956); Hermann FILLITZ, Die Reichskleinodien - Ein Versuch zur Erklärung ihrer Entstehung und Entwicklung, in: Heilig - Römisch - Deutsch. Das Reich im mittelalterlichen Europa, Internationale Tagung zur 29. Ausstellung des Europarates und Landesausstellung Sachsen-Anhalt, hg. von Bernd SCHNEIDMÜLLER / 
bei Rhein den Reichsapfel (oder die Sphaira) als Zeichen mittelalterlicher Weltherrschaft, ${ }^{56}$ der Markgraf von Brandenburg das Zepter als Zeichen monarchischer Hoheit. ${ }^{57}$ Die zeremonielle Darbietung des gesamten Ensembles in kurfürstlichen Händen kannte keine Vorbilder, ${ }^{58}$ auch wenn die Historiografie oder die Krönungsordines die liturgische Übertragung von Herrschaftszeichen in Erhebungs- oder Bekräftigungsakten seit ottonischer Zeit überlieferten. ${ }^{59}$ Für die Präsentation der Symbole kaiserlicher oder königlicher Macht gab es im gesamten Mittelalter keine einheitlichen Regelungen. Die überlieferten Beispiele bezeugten allerdings stets die hohe Bedeutung des rituellen Handanlegens an die konkreten Symbole der Monarchie. Doch längere zeitliche Verfestigungen beim Insignienführen in der Hand einzelner Gefolgsmänner sind kaum auszumachen. Selbst Karl IV. blieb trotz der Fixierungen der Goldenen Bulle letztlich inkonsequent, wenn er das Führen des Zepters oder des Reichsschwerts durch Gunsterweise an verschiedene Herren unterschiedlich und widersprüchlich regelte. ${ }^{60}$ Immer wieder überwanden konkrete Konstellationen die normativen Bestimmungen von scheinbar dauernder Geltungskraft. Diachrone Betrachtungen erweisen immer wieder die Dominanz permanenter Ritualdynamik über alle zeremonielle Statik. ${ }^{61}$

Zur Komplettierung des Aufzugs fügte man den Böhmenkönig ohne Insignien hinter den Kaiser. Dieser besondere Rang entsprang wohl auch der Achtung königlicher Würde, der das Tragen eines anderen monarchischen Herrschaftszeichens nicht zuzumuten war. Und ganz am Schluss der Prozession folgte hinter dem Böhmen mit

Stefan WeinfurTer (2006) S. 133-161. Zum Schwert vgl. Dagmar HÜPPER, Schwert, in: HRG 4 (1990) Sp. 1570-1574; Gernot Kocher, Schwert, in: Lex. MA 7 (1995) Sp. $1644 \mathrm{f}$.

56 Percy Ernst SchramM, Sphaira - Globus - Reichsapfel. Wanderung und Wandlung eines Herrschaftszeichens von Caesar bis zu Elisabeth II. Ein Beitrag zum „Nachleben“" der Antike (1958); Adalbert ERLER, Reichsapfel, in: HRG 4 (1990) Sp. 537 f.

57 Lorenz LAUbENBERGER, Zepter, in: HRG 5 (1998) Sp. 1669-1672; Heike DrechSLER, Zepter, in: Lex. MA 9 (1998) Sp. 544 f.

58 So Zeumer, Goldene Bulle (wie Anm. 4) 1 S. 88.

59 Eduard EICHMANN, Die Kaiserkrönung im Abendland. Ein Beitrag zur Geistesgeschichte des Mittelalters. Mit besonderer Berücksichtigung des kirchlichen Rechts, der Liturgie und der Kirchenpolitik, 2 Bde. (1942); Percy Ernst SCHRAMM, Kaiser, Könige und Päpste. Gesammelte Aufsätze zur Geschichte des Mittelalters, 4 Bde. in 5 Teilen (1968-1971).

60 Vgl. ZEUMER, Goldene Bulle (wie Anm. 4) 1 S. 89 und S. 239-244; PETERSOHN, Insignien (wie Anm. 55) S. 78 ff.

${ }^{61}$ Ritualdynamik. Kulturübergreifende Studien zur Theorie und Geschichte rituellen Handelns, hg. von Dietrich HARTH / Gerrit Jasper SCHENK (2004); Die neue Kraft der Rituale, hg. von Axel MiCHAELS (2007). 
angemessenem Abstand noch die Kaiserin oder römische Königin, begleitet von ihren Adeligen und von Jungfrauen. Die Distanz der im Wahlkönigtum dynastisch funktionslosen Herrscherin zum maskulinen Reich mit Haupt und Gliedern hätte kaum deutlicher ausgedrückt werden können. Die Unterschiede zur zeremoniellen Performanz von König und Königin in den europäischen Monarchien, in denen die Herrscherin als Garantin dynastischer Kontinuität herausragende Bedeutung behauptete, ${ }^{62}$ wären in vergleichenden Studien noch genauer aufzudecken.

Die Metzer Zusätze vom Weihnachtstag 1356 präzisierten und ergänzten diese Prozessionsordnung: ${ }^{63}$ An einem feierlichen Hoftag (solempnis curia) sollten die Kurfürsten den Kaiser oder König frühmorgens von seiner Herberge abholen, wo diesem die Insignien angelegt wurden. Dann folgte der Zug in der von den Kapiteln 21 und 22 festgelegten Ordnung zu Pferd. Dem Trierer Erzbischof an der Spitze wurden noch zwei Kronen vorangeführt, erst die Aachener, dann die Mailänder Krone. Träger waren niedere Fürsten (principes inferiores), vom Kaiser jeweils neu bestimmt. Mit ansprechenden Argumenten wurde das Mailänder Stück mit der von Karls Großvater Heinrich VII. in Auftrag gegebenen lombardischen Königskrone, die Aachener Insignie als Reliquienkrone Karls des Großen im dortigen Domschatz identifiziert. Gewiss handelte es sich um eine Idealbestimmung, da die Originale beider Kronen kaum gemeinsam für spätmittelalterliche Prozessionen zur Verfügung standen. ${ }^{64}$ Welche anhaltende Bedeutung sich die Sichtbarmachung des Reichs im kurfürstlichen Raumgefüge bewahrte, zeigten noch ganz am Ende des Alten Reichs geradezu anrührende juristische Bemühungen. Obwohl die Kurfürsten in der frühen Neuzeit kaum noch persönlich beim Kaiser erschienen und das personale Ensemble mühsam durch Ersatzbestimmungen aufrecht erhalten werden musste, ${ }^{65}$ entwarf Nicolaus Thaddäus Gönner in seinem ,Teutschen Staatsrecht' von 1804 - also nach den Umwälzungen des Reichsdeputationshauptschlusses - eine aktuelle Lateral-, Linealund Prozessionsordnung der alten und neuen Kurfürsten, unter denen „im Sitzen und Gehen dreierlei Ordnungen“ stattfünden: „Die Prozessionalordnung bei der

62 Vgl. Carsten WolL, Die Königinnen des hochmittelalterlichen Frankreich 987-1237/38 (Historische Forschungen 24, 2002); Amalie FöSSEL, Die Königin im mittelalterlichen Reich. Herrschaftsausübung, Herrschaftsrechte, Handlungsspielräume (Mittelalter-Forschungen 4,2000 ).

MGH Const. 11 S. 620,25-622,11 (Kap. $26 \S 1$ ); vgl. HeRgEMÖLLER, Abschluß (wie Anm. 11) S. 212-215.

64 Petersohn, Insignien (wie Anm. 55) S. 83-85.

65 Barbara Stollberg-RiLinger, Das Reich als Lehnssystem, in: Heiliges Römisches Reich Deutscher Nation 962 bis 1806. Altes Reich und neue Staaten 1495 bis 1806. 29. Ausstellung des Europarates in Magdeburg und Berlin 2: Essays, hg. von Heinz ScHILLING / Werner HEUN / Jutta GÖTZMANN (2006) S. 5567. 
feierlichen Krönungsprozession, mit und ohne Insignien, bedarf nach der grossen Veränderung, die sich unter den Kurfürsten ergeben hat, einer neuen Bestimmung, auf welche selbst die den neuen Kurfürsten zu verleihenden Erzämter nicht ohne Einfluss seyn werden." In seinem Schema schied der Jurist den Erzbischof von Trier aus und baute die vom 17. bis zum 19. Jahrhundert neu hinzugekommenen Kurfürsten von Braunschweig, Salzburg, Baden, Hessen und Württemberg in die Sitzordnung ein. Für alle Fälle, so möchte man diese theoretische Neufassung beurteilen, hielt man sich das untergehende Reich als Raumgefüge von Kaiser und Kurfürsten präsent. ${ }^{66}$

\section{Dienst als Ehre}

Neben dem Sitzen und dem Gehen gestalteten ausführliche Passagen der Goldenen Bulle die symbolische Interaktion von König und Kurfürsten. Eben erst durch Wahl aus dem Kreis der fürstlichen Standesgenossen erhoben, demonstrierten öffentliche Unterwerfungsrituale der Kurfürsten die Unterordnung in der Gleichrangigkeit. Seit dem früheren Mittelalter hatte man den Hof als Handlungsverbund des Herrn und der Inhaber von Hofämtern beschrieben. ${ }^{67}$ Im 13 . Jahrhundert verbanden sich die vornehmsten Hofämter mit den vier weltlichen Königswählern: Als Erztruchsess agierte der Pfalzgraf bei Rhein und erhielt sich dieses besondere Erzamt auch nach seiner Verdrängung auf den zweiten Platz der weltlichen Königswähler. Der König von Böhmen amtete als Erz(mund)schenk, der Herzog von Sachsen als Erzmarschall, der Markgraf von Brandenburg als Erzkämmerer. ${ }^{68}$ Die Hofamtsbezeichnungen behaupteten sich bis zum Ende des Alten Reichs und wurden beim frühneuzeitlichen Anwachsen des Kurfürstenkollegs um neue Erzämter erweitert.

66 Nicolaus Thaddäus GöNNER, Teutsches Staatsrecht (1804) § 147 S. 206-208, die Zitate S. $207 \mathrm{f}$. Den Hinweis auf dieses Werk verdanke ich Gerald Schwedler (Zürich).

67 Werner RöSENER, Hofämter an mittelalterlichen Fürstenhöfen, DA 45 (1989) S. 485-550. Zu den vier Hof- und Erzämtern im Einzelnen vgl. F. STIX, Kämmerer, in: HRG 2 (1978) Sp. 574 576; Peter SCHMID, Marschall, in: HRG 3 (1984) Sp. 348-353; Reiner SCHULZE, Schenk, in: HRG 4 (1990) Sp. 1376-1382; Kurt ANDERMANN, Truchseß, in: HRG 5 (1998) Sp. 374-377.

Egon BosHOF, Erstkurrecht und Erzämtertheorie im Sachsenspiegel, in: Beiträge zur Geschichte des mittelalterlichen deutschen Königtums, hg. von Theodor SCHIEDER (HZ Beih. 2, 1973) S. 84-121; Franz-Reiner ERKENS, Kurfürsten und Königswahl. Zu neuen Theorien über den Königswahlparagraphen im Sachsenspiegel und die Entstehung des Kurfürstenkollegiums (MGH Studien und Texte 30, 2002). 


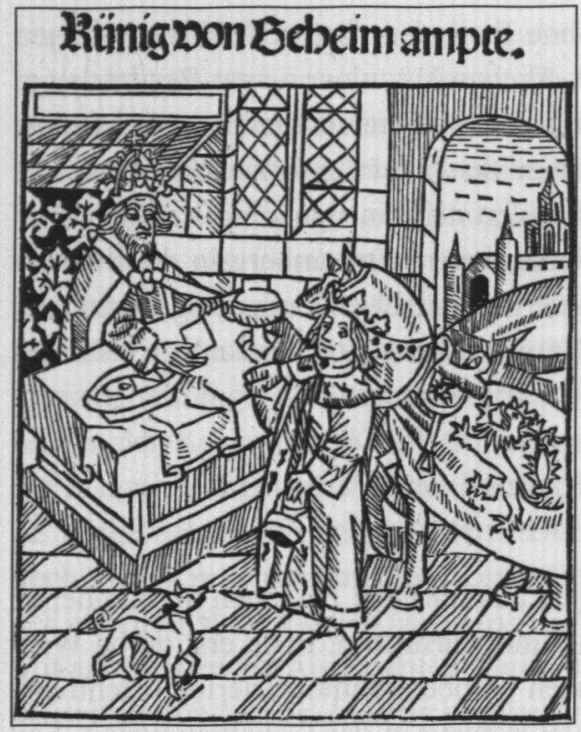

Abbildung 5

Der König von Böhmen als Erzmundschenk

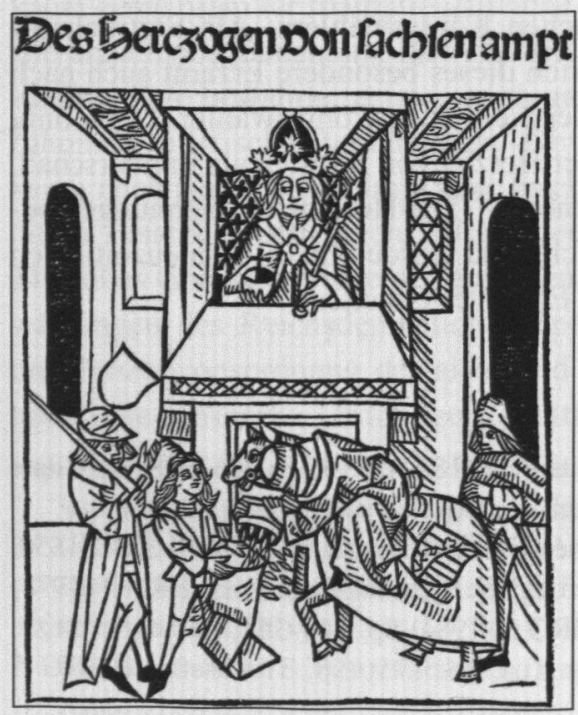

Abbildung 7

Der Herzog von Sachsen als Erzmarschall

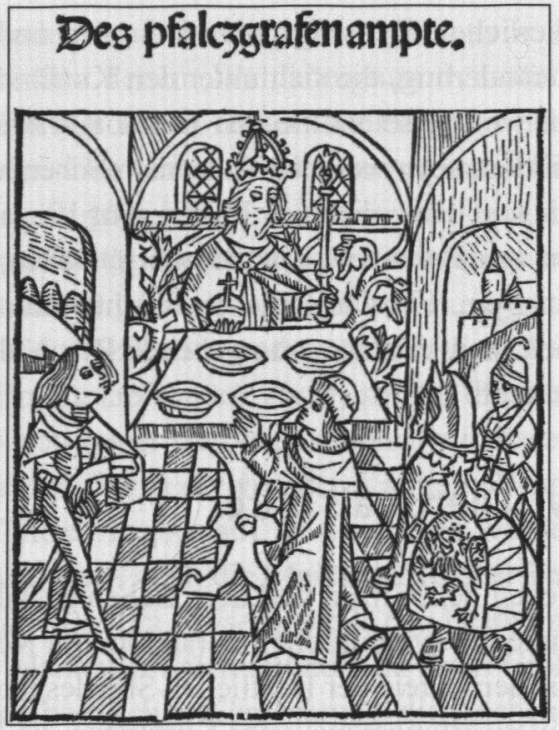

Abbildung 6

Der Pfalzgraf bei Rhein als Erztruchsess

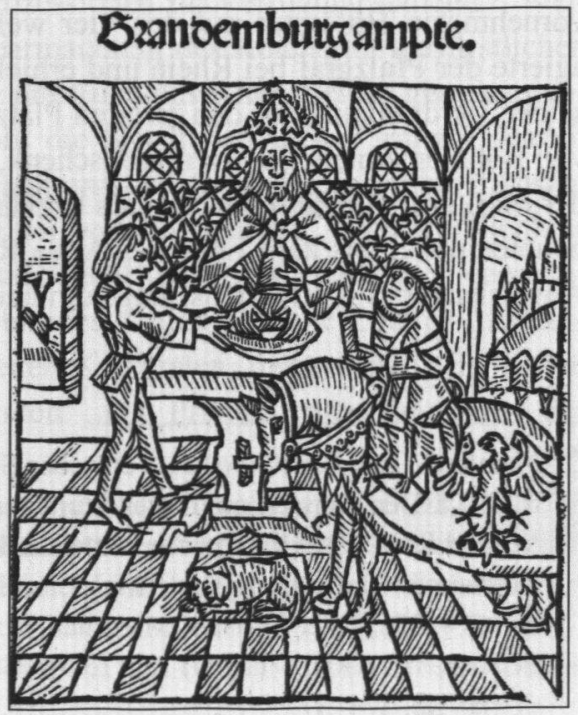

Abbildung 8

Der Markgraf von Brandenburg als Erzkämmerer

Abbildungen 5-8

Die Hofämter der weltlichen Kurfürsten.

Holzschnitte aus der Inkunabel GW 4081 der Goldenen Bulle (Straßburg 1485) 
Die Goldene Bulle fügte die Kurwürde mit dem Erzamt zusammen und schrieb vor, dass der Markgraf von Brandenburg dem Herrscher das Wasser zum Händewaschen, der König von Böhmen ohne Königskrone auf dem Haupt den ersten Trunk und der Pfalzgraf das Essen reichen solle, während der Herzog von Sachsen das Marschallamt ausübte. Diese Reihenfolge ist von der Praxis des Mahls bestimmt, erst das Händewaschen, dann der Trunk, schließlich das Essen. Die Metzer Zusätze vom Weihnachtstag 1356 präzisierten das zeremonielle Miteinander.

Besonders ausführlich beschrieb Kapitel 27 die Hofämter der Kurfürsten mit ihren Pflichten auf Hoftagen. ${ }^{69}$ Die Reihenfolge beim Tischdienst der Kurfürsten erwuchs nicht aus dem Rang, sondern aus der Bewegung des Hoftags. Wie andere lebende Bilder des Spätmittelalters präsentierte sich das Reich als Tableau vivant. ${ }^{70}$ Das Marschallamt verlangte vom Herzog von Sachsen folgendes Ritual: Vor dem herrscherlichen Sitzungsgebäude musste ein Haufen Hafer aufgeschüttet werden, der bis zur Brust oder zum Brustriemen des herzoglichen Pferds reichte. Der Sachse sollte einen Stab und einen Maßkorb aus Silber im Gewicht von zwölf Mark halten, den Maßkorb mit Hafer füllen und ihn dem ersten vorbeikommenden Knecht reichen. Dieser explizit präsentierte Überfluss an Hafer im höfischen Zeremoniell konnte nur von einer Gesellschaft begriffen werden, der das Pferd als das entscheidende Transportmittel und Statussymbol selbstverständlich war. Über die Zeiten blieb bis ins 20. Jahrhundert hinein die Versorgung mit Raufutter die entscheidende logistische Herausforderung für alle Reiterkrieger. Darum garantierte die inszenierte Fülle des Hafers geradezu die Opulenz des kaiserlichen Ensembles. ${ }^{71}$

Die Gabe im Wert von zwölf Mark Silber kennzeichnete auch die Dienste der anderen Kurfürsten, ein Geschenk in einer privilegierten Konsensgemeinschaft, das Überund Unterordnung in flachen Hierarchien symbolisierte. ${ }^{72}$ Vor dem Mahl sollten die Erzbischöfe den Tischsegen spenden, bevor sich der Herrscher zur Tafel begab.

69 Vgl. Hergemöller, Abschluß (wie Anm. 11) S. 215-220; Gerald SchWEDLER, Dienen muß man dürfen oder: Die Zeremonialvorschriften der Goldenen Bulle zum Krönungsmahl des römisch-deutschen Herrschers, in: Die Welt der Rituale. Von der Antike bis heute, hg. von Stefan WEINFURTER / Claus AMBos / Stephan HotZ / Gerald SCHWEDLER (2005) S. 156-165.

70 Martin KINTZINGER, Zeichen und Imaginationen des Reichs, in: Heilig - Römisch Deutsch (wie Anm. 55) S. 345-371.

71 Diesen Hinweis verdanke ich Joachim Ehlers (Berlin). Vgl. M. RösCH, Hafer, in: Hoops ${ }^{2}$ 13 (1999) S. 322-324; H. REICHSTEIN / St. ZIMMER, Pferd, in: HOOPS 23 (2003) S. $24-35$.

72 Zur Symbolik der Gabe Marcel MaUSS, Die Gabe. Form und Funktion des Austauschs in archaischen Gesellschaften, übers. von Eva MOLDENHAUER (suhrkamp taschenbuch wissenschaft 743, 1990); Negotiating the Gift. Pre-Modern Figurations of Exchange, hg. von Gadi AlgAZI / Valentin GroEBNER / Bernhard JusSEN (VMPIG 188, 2003). 
Als Erzkanzler und Ehrenvorsteher der Kanzlei empfingen sie vom Hofkanzler die königlichen Siegel an einem Stab. Dieser hatte ein Gewicht von zwölf Mark Silber, je zu einem Drittel von den drei Erzbischöfen bezahlt.

Zwölf Pfund Silber wogen die beiden silbernen Wasserbecken, die der Markgraf von Brandenburg als Erzkämmerer zu Pferd mit einem schönen Handtuch heranführte. Nach dem Absteigen reichte er dem Herrscher die Becken zum Händewaschen. Auch der Pfalzgraf bei Rhein als Erztruchsess kam zu Pferd, mit vier Schüsseln im Gewicht von zusammen zwölf Mark Silber. Nach dem Absteigen reichte auch er dem Herrscher die Schüsseln voller Speisen. Und schließlich brachte der König von Böhmen als Erzmundschenk einen silbernen Pokal voll Wein und Wasser im Gewicht von zwölf Mark Silber, den er nach dem Absteigen vom Pferd dem Kaiser oder römischen König zum Trunk anbot. Während dem Herrscher die symbolischen Dienste geleistet wurden, erhielten Personen des königlichen Haushalts anschließend nach einem genauen Verteilungsschlüssel die dargebrachten Gaben als Lohn.

Ein solcher ordo mit seinen detaillierten Vorschriften mutet geradezu archaisch an. Wie wollte man diese Pergament verschwendende Ausgestaltung der Speisegemeinschaft erklären? Wurden hier ältere Schichten des Hauses mit dem Herrn und seinen Knechten verschriftlicht und auf das Miteinander von König und Kurfürsten im spätmittelalterlichen Reich übertragen? Da es keine Belegreihen von frühmittelalterlichen Konstrukten zu spätmittelalterlichen Inszenierungen gibt, ${ }^{73}$ sollten wir die Regelungen aus dem zeremoniellen Wollen des 14. Jahrhunderts begreifen.

Das mangelnde moderne Interesse an diesem Kapitel steht in diametralem Gegensatz zu seiner Beliebtheit in der mittelalterlichen Überlieferung. Schon der Prachtcodex aus der Hofwerkstatt König Wenzels um 1400, eine der ältesten der mehr als 70 vollständig erhaltenen lateinischen Abschriften des Mittelalters, setzte die Hofdienste in farbigen Miniaturen in Szene. ${ }^{74}$ Der erste illustrierte Druck der Goldenen Bulle (Straßburg 1485) nahm insgesamt nur elf kostbare Holzschnitte auf. Aber die im Kapitel 27 genannten Dienste der Hofamtsträger wurden in Gänze auf sechs Holzschnitten präsentiert. Ein weiterer zeigte zum 3. Kapitel die Bestimmungen

73 ZEUMER, Goldene Bulle (wie Anm. 4) 1 S. 93: „Quellen für diese Kapitel vermag ich nicht nachzuweisen; nur für c. XXVII ist eine uns nicht überlieferte Vorlage mit großer Wahrscheinlichkeit anzunehmen." Ein berühmtes, in dieser Form erstmaliges Vorbild des herzoglichen Tischdiensts beim Krönungsmahl 936 in Aachen bot Widukind von Corvey: Die Sachsengeschichte des Widukind von Korvei (Widukindi monachi Corbeiensis Rerum gestarum Saxonicarum libri III), hg. von Paul HiRSCH / Hans-Eberhard LOHMANN (MGH SS rer. Germ. 60, 1935) S. 66 f. (Kap. II 2).

7 Benutztes Faksimile: Die Goldene Bulle. König Wenzels Handschrift. Codex Vindobonensis 338 der Österreichischen Nationalbibliothek, Kommentar von Armin WoLF (Glanzlichter der Buchkunst 11, 2002). 
zur Tischordnung (allerdings aus Kap. 28) ${ }^{75}$ Rituelle Akte - genau das waren die Darstellungen, die man sich im 15. Jahrhundert wünschte! Noch die neuzeitlichen Krönungsdiarien hielten akribisch vor allem die Dienste anwesender Kurfürsten fest. $^{76}$ In den Jahrhunderten vor der Institutionalisierung und Abstrahierung des Staates begegneten im Sitzen, Gehen und Dienen von König und Kurfürsten die Wurzelgründe der Gemeinschaft und des Zusammenhalts. Solche Inszenierungen brachten das Reich hervor, machten es sichtbar, konturierten seine Besonderheiten.

\section{Vergleichende Perspektiven}

Greifen wir noch einmal den Vergleich mit dem Königreich Frankreich auf und nehmen ein Ritualpräskript für das englische Parlament des 14. Jahrhunderts hinzu, so treten die Unterschiede dreier Herrschaftsmodelle deutlicher hervor. Kaiser Karl IV. handelte die Goldene Bulle mit den Kurfürsten und den Gliedern des Reichs aus und veröffentlichte sie dann auf zwei Hoftagen in Nürnberg und Metz. Originale des Kaiserlichen Rechtsbuchs gelangten an fünf der sieben Kurfürsten sowie an die Städte Frankfurt am Main und Nürnberg. ${ }^{77}$ König Karl V. von Frankreich entwickelte seine Ordonnanzen 1374 mit den Ratgebern seines Hofs, betonte aber auch den breiten Herrschaftskonsens seiner Fürsten. Die Promulgation fand am 21. Mai 1375 in einer feierlichen Sitzung des Parlement in Paris statt. Neben dem König nahmen sein ältester Sohn, der spätere Karl VI., und sein Bruder Herzog Ludwig von Anjou mit weiteren Verwandten teil, dazu Prälaten, die Universität Paris und viele bedeutende Kleriker wie Laien. ${ }^{78}$ Karl V. nutzte dafür ein ,Lit de justice', jene feierliche Präsentation

75 Die güldin bulle (wie Anm. 27) Faksimile fol. VIIr zu Kap. 3 (Tischordnung, im Holzschnitt allerdings die Bestimmungen von Kap. 28); zu Kap. 27 ebd. fol. XVIv (Aufzug der drei Erzbischöfe mit den Siegeln am silbernen Stab), fol. XVIIr (Hofamt des Herzogs von Sachsen), fol. XVIIv (Tischsegen der drei Erzbischöfe), fol. XVIIIr (Hofamt des Markgrafen von Brandenburg), fol. XVIIIv (Hofamt des Pfalzgrafen bei Rhein), fol. XIXr (Hofamt des Königs von Böhmen); siehe Abb. 5-8 der Hofämter. Die Bedeutung dieser sieben Holzschnitte zu Zeremonialvorschriften wird noch deutlicher, weil alle anderen Kapitel zusammen mit nur vier Bildern versehen sind: fol. IIr (Vorrede), fol. IIIr (Kap. 1 mit Einzug der Kurfürsten nach Frankfurt am Main), fol. Vv (Kap. 2 mit Messe), fol. XIr (Kap. 12 mit Zusammenkunft der Kurfürsten).

76 Vgl. WANGER, Kaiserwahl (wie Anm. 34); Barbara DölEMEYER, Reichsrecht, politische Propaganda und Festbeschreibung in den Wahl- und Krönungsdiarien, in: Die Kaisermacher. Aufsätze (wie Anm. 1) S. 140-151. Zur Überlieferung vgl. MGH Const. 11 S. 540 f.

78 Les grandes chroniques de France: Chronique des règnes de Jean II et de Charles V, hg. von Roland DelachenAL, 4 Bde. (SHF, 1910-1920), hier 2 S. 177. Weitere Anwesende: 
auf dem Thron en sa magnificence ou majesté royale. ${ }^{79}$ Das, Bett der Gerechtigkeit' - auch hier hatte sich ein älteres Ritual ins Spätmittelalter verwandelt. Von Ludwig dem Heiligen wurde erzählt, dass er vom Fuß seines Bettes Recht sprach, also am Ort des Übergangs von privater Vertrautheit zur politischen Öffentlichkeit. ${ }^{80}$ Wenig beachtet ist in diesem Zusammenhang der Bericht Richers von Reims vom Treffen des westfränkischen Königs Ludwig IV. mit dem ostfränkischen König Otto I. 940 in Attigny. Beide Könige saßen im Beisein westfränkischer Großer auf einem Bett, als der Normannenherzog Wilhelm Anstoß an der vornehmeren Positionierung Ottos auf dem erhöhten Kopfende gegenüber derjenigen Ludwigs auf dem niedrigeren Fußende nahm. ${ }^{81}$ Schon im 10. Jahrhundert entwickelte sich das herrscherliche Bett also zum öffentlich gemachten Zeremonialort der Politik. Im Laufe der Zeit entwickelte sich dann in Frankreich aus dem Bett des Königs der feierliche Herrscherthron im Parlement.

Zu den weltlichen Pairs de France zählten inzwischen vor allem die Prinzen von Geblüt als enge Verwandte der französischen Könige. ${ }^{82}$ Während im Imperium die

Ordonnances des rois de France de la troisième race 6(1741) S. 30. Zum Parlement vgl. Françoise AuTrand, Naissance d'un grand corps de l'état. Les gens du Parlement de Paris 1345-1454 (Publications de la Sorbonne. Série NS recherche 46, 1981); Gisela NAEGLE, Stadt, Recht und Krone. Französische Städte, Königtum und Parlement im späten Mittelalter, 2 Bde. (Historische Studien 468, 2002); zuletzt die Beiträge in: Histoire et archives 19 (2006).

79 Sarah HANLEY, The Lit de justice of the Kings of France. Constitutional Ideology in Legend, Ritual, and Discourse (Studies Presented to the International Commission for the History of Representative and Parliamentary Institutions 65, 1983); Elizabeth A. R. Brown / Richard C. FAmiglietTi, The Lit de Justice: Semantics, Ceremonial, and the Parlement of Paris (Francia Beih. 31, 1994).

80 Zur Symbolik vgl. Karin LERCHNER, Lectulus floridus. Zur Bedeutung des Bettes in Literatur und Handschriftenillustration des Mittelalters (Pictura et poesis 6, 1993); Klaus VAN EICKELS, Vom inszenierten Konsens zum systematisierten Konflikt. Die englischfranzösischen Beziehungen und ihre Wahrnehmung an der Wende vom Hoch- zum Spätmittelalter (Mittelalter-Forschungen 10, 2002) S. 368 ff.; OsCHEMA, Freundschaft (wie Anm. 42) S. $538 \mathrm{ff}$.

81 Richer von Saint-Remi, Historiae, hg. von Hartmut HoffmanN (MGH SS 38, 2000) S. 119 f. (Kap. II 30 f.). Zu dieser Passage Bernd SCHNEIDMÜLLER, Wahrnehmungsmuster und Verhaltensformen in den fränkischen Nachfolgereichen, in: Deutschland und der Westen Europas im Mittelalter, hg. von Joachim EhLERS (VuF 56, 2002) S. 263-302, hier S. 283.

82 Richard A. JACKSON, Peers of France and Princes of Blood, French Historical Studies 7 (1971) S. 27-46. Zu Genese und Bedeutung der Pairs de France Percy Ernst Schramm, Der König von Frankreich. Das Wesen der Monarchie vom 9. zum 16. Jahrhundert, 2 Bde. ('1960) S. 171 ff.; Philippe ConTAmINE, Les pairs de France au sacre des rois (XVe siècle). 
Kurfürsten dem Herrscher als Korporation entgegentraten, saugte die französische Königsfamilie ihre Pairs regelrecht auf. Darum erhielten diese auch keine Exemplare der Ordonnanzen. Die Originale wanderten vielmehr in dreifacher Ausfertigung in den königlichen Urkundenschatz, den Trésor des chartes de France. Lediglich das Königskloster Saint-Denis erlangte eine Abschrift in Form eines Originals zur Verwahrung, auf dem die Anwesenheit der Großen des Reichs namentlich notiert wurde ${ }^{83}$ Kaum etwas könnte deutlicher die Unterschiede zwischen Imperium und Regnum demonstrieren als die Publikation und Überlieferung solcher Fundamentalakte.

Im August 1374 veröffentlichte Karl V. von Frankreich in Vincennes seine große Ordonnanz in lateinischer Sprache über die Thronfolge seines erstgeborenen Sohnes. Auch später sollte der erstgeborene Sohn seiner Nachfolger oder - beim Tod des Erstgeborenen - der jeweils nächstgeborene Bruder oder dessen ältester männlicher Nachkomme das Königtum erlangen und die Regierungsgeschäfte übernehmen, sobald er den 14. Geburtstag erreicht hatte. ${ }^{84}$ Diese Bestimmungen systematisierten das bisherige französische Thronfolgerecht, das gerade im Hundertjährigen Krieg mit England harte Bewährungsproben bestand. Mit seiner gelehrten Umgebung schrieb der König die Prinzipien der Primogenitur und des Ausschlusses der Frauen vom Thron fest, die französische Kronjuristen später mit eigentlich völlig anders gerichteten erbrechtlichen Bestimmungen der frühmittelalterlichen ,Lex Salica' in Verbindung brachten. ${ }^{85}$ Aus der Selbstvergewisserung der Valois von der eigenen Legitimität erwuchsen normative Bestimmungen für die Zukunft. Gewiss zielten sie zuvorderst auf die bevorstehende Sukzession Karls VI. und auf die aktuellen Konstellationen in der Familie Karls V. Doch die situativen Maßnahmen wurden in biblische, fränkische und französische Traditionen von langer Dauer eingebettet und in die Form eines Fürstenspiegels gegossen, der zur tragfähigen Grundlage von zukünftiger Legitimität - bis zum Ende der Monarchie in Frankreich - erwuchs.

Nature et portée d'un programme iconographique, Bull. de la Société Nationale des Antiquaires de France (1988) S. 321-347; Pierre DESPORTES, Les pairs de France et la couronne, in: RH 282 (1989) S. 305-340.

83 Zur Überlieferung HECKMANN, Stellvertreter (wie Anm. 3) S. 758; Roland DELACHENAL, Histoire de Charles V 4 (1928) S. 530-540.

84 Druck bei HeckmanN, Stellvertreter (wie Anm. 3) S. 758-762 Nr. 19-21. Mit dieser Ausgabe wird der bisher üblicherweise zitierte ältere Druck ersetzt: Ordonnances (wie Anm. 78) 6 S. 26-31.

85 Im Überblick Helmut SCHEIDGEN, Die französische Thronfolge (987-1500), der Ausschluss der Frauen und das salische Gesetz (Diss. Bonn 1976); Andrew W. LEwIS, Royal Succession in Capetian France: Studies on Familial Order and the State (Harvard Historical Studies 100, 1981). 
Obwohl an keiner Stelle explizit formuliert, kann die Ordonnanz vom August 1374 gleichzeitig als prägnanter Gegenentwurf zur Goldenen Bulle Kaiser Karls IV. und der Kurfürsten von 1356 gelesen werden. Die ausführliche Arenga entwarf eine dezidierte Erziehungslehre für den künftigen Monarchen, Gedanken für den guten Umgang zwischen den Generationen in der Königsfamilie und Regeln für das Miteinander der Geschwistergemeinschaft wie für die Bevorzugung des Primogenitus als Thronfolger. ${ }^{86}$ Dieser erlangte sein Amt sogleich beim Tod des Vaters, und mit vierzehn Jahren konnte ein Monarch selbständig regieren. Um solch frühe Befähigung zu rechtfertigen, griff die Ordonnanz auf jugendliche Könige des Alten Testaments wie Joas (König im siebten Lebensjahr), Josias (König mit acht Jahren), David oder Salomo zurück. ${ }^{87}$ Das vierzehnte Lebensjahr unterschied die Kindheit von der Selbständigkeit. Als leuchtendes Vorbild für die Monarchie stellte Karl V. seinen heiligen Vorfahren heraus, König Ludwig IX. von Frankreich (1226-1270). ${ }^{88}$ Mit 14 Jahren trat er die selbständige Regierungsgewalt an, empfing die Lehnseide und Treueschwüre der Prälaten, Pairs sowie anderer Vasallen und erlangte Salbung und Krönung. Der heilige Ludwig, von der Welt bewundert, durchschritte wie die Sonne den Himmelsbogen und gelte als Blume, Schmuck, Licht und Spiegel für das königliche Geschlecht wie für alle Franzosen (Gallici) ${ }^{89}$ Endlich führte die Ordonnanz mit einem ungenannten minderjährigen Makedonenkönig und mit Chilperich I. noch zwei wagemutige minderjährige Könige aus der makedonischen und merowingischen Geschichte als Beispiele für frühe Eignung an. ${ }^{90}$ Zur Vermeidung von innerer Zwietracht und zum Erhalt des ruhigen Zustands seines Reichs habe Karl V. darum nach Beratung mit vielen Prälaten und hervorragenden Personen, Klerikern wie Laien, die Thronfolgeordnung aus königlicher Machtvollkommenheit als sein dauerhaftes Gesetz aufgerichtet. ${ }^{91}$

Die knappen und prägnanten Formulierungen dieser Ordonnanz wurden in Schriften aus der königlichen Umgebung vorgedacht, formuliert und weitergeführt. Als maßgebliche Berater wird man Philippe de Mézière, den Vorsitzenden des Vormundschaftsrats für den Thronfolger, Évrart de Trémaugon, den Verfasser des, Songe du Vergier' und späteren Bischof von Dol, oder Nicole Oresme, den berühmten Autor von Aristoteles-Kommentaren und späteren Bischof von Lisieux, nennen.

\footnotetext{
Dazu ausführlicher HECKMANN, Stellvertreter (wie Anm. 3) S. 199 ff.

Druck ebd. S. 759.

Jacques LE GOFF, Ludwig der Heilige (2000).

Druck bei HeckmanN, Stellvertreter (wie Anm. 3) S. 760, zur Sache ebd. S. 203 f.

Druck ebd. S. 760 f.; vgl. ebd. S. 205.

Druck ebd. S. 761.
} 
Wenige Wochen später ergänzte König Karl V. seine Bestimmungen von Vincennes durch zwei Ordonnanzen in französischer Sprache, die er im Oktober 1374 in Melun ausstellte. Hier regelte er eingehend die Vormundschaft über seine Kinder bis zum 14. Geburtstag des Thronfolgers durch einen Verwandtschaftsrat unter seiner Gemahlin Königin Johanna und den Herzögen Philipp dem Kühnen von Burgund und Ludwig II. von Bourbon. Ihnen wurde ein zahlreicher Berater- und Helferkreis zugesellt. Die ausgesprochene Größe des Gremiums sollte offensichtlich die Einflussnahme einer kleinen Clique auf die königlichen Kinder verhindern und der Verschleuderung königlicher Güter vorbeugen. Eingehende Kontrollmechanismen traten im vergleichsweise langen Text dieser Ordonnanz ebenso deutlich hervor wie die dezidierte Trennung von vormundschaftlicher Erziehung und Regentschaft. ${ }^{92}$

Den Kreis schloss in Melun eine weitere Ordonnanz vom Oktober 1374, welche beim vorzeitigen Ableben des Königs die Regentschaft über den Thronfolger bis zu dessen 14. Lebensjahr den handlungsfähigen Verwandten mit kleinteiligen Ersatzund Einzelbestimmungen zuwies. Geregelt wurde die Rolle der Königin wie der Herzöge Ludwig I. von Anjou und Touraine sowie Philipp II. von Burgund (Brüder des Königs) und Ludwig II. von Bourbon (Bruder der Königin). Mutter und Onkel aus väterlicher wie mütterlicher Verwandtschaft sollten den jungen König bis zur Regierungsfähigkeit begleiten. ${ }^{93}$

Geschickt verschränkten diese drei Ordonnanzen das Vorrecht des singulären Thronfolgers mit der Fürsorge und Ausstattung der ganzen königlichen Familie. Die Texte bestechen in ihrer Aussagekraft für die konkret anstehende Thronfolge wie für das französische Königtum insgesamt. Gewiss - die Regelungen der Goldenen Bulle von 1356 und der drei Ordonnanzen von 1374 sind in den Einzelheiten unvergleichlich. Doch sie entwarfen zwei Modelle monarchischer Existenz, die in unterschiedlicher Weise zeremonieller Auskleidung bedurfte. Auf der einen Seite stand die Kontinuität des Imperiums, das sich in der Folge von Wahl- und Konsensakten konstituierte. Auf der anderen Seite präsentierte sich das französische Königtum in der erbrechtlich begründeten Folge von Vätern und Söhnen, im kunstvoll gesponnenen Netz von Dynastie und Reich, im sicheren Rückgriff auf eine lange und vornehme Geschichte, die alttestamentliche Könige mit makedonischen und merowingischen Herrschern als Vorbildern und dem heiligen Ludwig als kraftspendendem Legitimationsquell seiner Nachkommen verwob.

Hinzu kamen Differenzen in der Idealisierung politischen Handelns: Während die Politik des Imperiums von einer hocharistokratischen Gemeinschaft aus Kaiser und

92 Druck bei HeckmanN, Stellvertreter (wie Anm. 3) S. 763-773 Nr. 22. Dieser Druck ersetzt: Ordonnances (wie Anm. 78) 6 S. 49-54.

93 Druck bei HECKMANN, Stellvertreter (wie Anm. 3) S. 773-778 Nr. 23. 
Kurfürsten gestaltet wurde, entwickelte der Hof der Valois das Leitbild eines weisen und von klugen Ratgebern umgebenen Königs. ${ }^{94}$ Ihm standen viele Helfer zur Seite, die ganz dezidiert unterschiedlichen ständischen wie funktionalen Eliten entstammten. Früh schon integrierten die französischen Herrscher ihre engsten Verwandten, den Klerus und den Adel mit der Universität und der Stadt Paris in ihrem Hof. Solche Personenverbände und Imaginationsräume idealen Herrschens warfen lange Schatten: hier die Partizipation fürstlicher Landesherren, dort die Politikberatung durch eine intellektuelle Funktionselite.

Der englische ,Modus tenendi parliamentum', auf Grund seiner ungeklärten Entstehung und Funktion ein schwierig zu interpretierender Text des 14. Jahrhunderts, ${ }^{95}$ entfaltete die Spannbreite politischer Inszenierung um ein wichtiges drittes Beispiel. Die Vorschriften zur Abhaltung und zur Ausgestaltung der Parlamentsversammlungen $^{96}$ brauchen nicht als Spiegel der Realität gelesen $z u$ werden und entsprangen kaum den Intentionen der Monarchie. Vielmehr lässt sich das Interesse an einer verbindlichen Verpflichtung des Königs auf die politischen Spielregeln des Miteinanders

94 Christine de Pisan, Le Livre des fais et bonnes meurs du sage roy Charles V, hg. von Suzanne SolEnTE, 2 Bde. (1936-1940); Le Songe du vergier. Édité d'après le manuscrit royal 19 C IV de la British Library, hg. von Marion SCHNERB-LıÈvre, 2 Bde. (SHM, 1982); Somnium viridarii, hg. von Marion Schnerb-Lièvre, 2 Bde. (SHM, 19931995). Vgl. Autrand, Charles V (wie Anm. 5); Heckmann, Stellvertreter (wie Anm. 3) S. $199 \mathrm{ff}$; Jacques KRYNEN, Idéal du prince et pouvoir royal en France à la fin du moyen àge (1380-1440). Étude de la littérature politique du temps (1981); Joachim EHLERS, Geschichte Frankreichs im Mittelalter (1987) S. 241 ff. Zu Voraussetzung und Wirkung Jacques KRYNEN, L'empire du roi. Idées et croyances politiques en France, XIII $-\mathrm{XV}^{\mathrm{e}}$ siècle (1993).

Untersuchung und Edition der beiden Rezensionen A und B der englischen Version des ,Modus tenendi parliamentum': Parliamentary Texts of the Later Middle Ages, hg. von Nicholas Pronay / John TAYlor (1980) S. 11-114. Frühere Ausgabe bei Maude V. ClarKe, Medieval Representation and Consent. A Study of Early Parliaments in England and Ireland, with Special Reference to the Modus Tenendi Parliamentum ( $\left.{ }^{2} 1964\right)$, Edition der englischen Version S. 373-384. Zum Text, seinen Ursprüngen, seiner Datierung und Funktion vgl. Michael PRESTwiCH, The Modus Tenendi Parliamentum, Parliamentary History 1 (1982) S. 221-225; Kathryn KERBY-Fulton / Steven JuSTICE, Reformist Intellectual Culture in the English and Irish Civil Service: The Modus Tenendi Parliamentum and its Literary Relation, Traditio 53 (1998) S. 149-202; W. C. WEBER, The Purpose of the English Modus Tenendi Parliamentum, Parliamentary History 17 (1998) S. 149-177.

96 Zum historischen Wandel vom 13. zum 14. Jahrhundert Michael PrESTWICH, Plantagenet England 1225-1360 (2005); Literaturhinweise zum Parlament ebd. S. 593, zum ,Modus' S. 224-226. 
deutlich erkennen, möglicherweise aus den Perspektiven eines klerikalen Beamten des Parlaments formuliert. Schon die Vorrede sprach vom Parlament des Königs von England und seiner Engländer. Um den Bestimmungen Geltungskraft zu verleihen, führte der Vorspann die Parlamentssitzungen in die angelsächsische Königszeit Eduards des Bekenners (1042-1066) zurück und erwähnte die ausdrückliche Bestätigung durch Wilhelm den Eroberer. ${ }^{97}$ Damit verband sich der Ursprung politischer Ordnung mit der Gelenkstelle englischer Geschichte im Übergang von der angelsächsischen zur anglonormannischen Epoche. Dieser Wille zur uralten historischen Fundierung entsprach der mittelalterlichen Rückführung der französischen Monarchie auf trojanische Ursprünge ${ }^{98}$ oder der Lehre von der Begründung des Kurfürstenkollegs durch Karl den Großen, Otto III. oder Papst Gregor V., wie sie im Imperium seit dem 13. Jahrhundert - ausgehend von Martin von Troppau - in verschiedenen Varianten entwickelt wurde..$^{99}$

97 Parliamentary Texts (wie Anm. 95) S. 67 (Rec. A) und S. 103 (Rec. B); Clarke, Medieval Representation (wie Anm. 95) S. 374.

98 Colette BEAUNE, Naissance de la nation France (1985); Troia. Traum und Wirklichkeit. Katalog zur Ausstellung 2001/2002 (2001).

99 Max BuCHNER, Die Entstehung und Ausbildung der Kurfürstenfabel. Eine historiographische Studie (1912); Edmund E. STENGEL, Der Heerkaiser (Den Kaiser macht das Heer). Studien zur Geschichte eines politischen Gedankens, in: DERS., Abhandlungen und Untersuchungen zur Geschichte des Kaisergedankens im Mittelalter (1965) S. 1-169, zur Begründung von Königswahl und Kurkolleg durch Karl den Großen siehe dort den Exkurs II S. 150-169; Winfried BECKER, Der Kurfürstenrat. Grundzüge seiner Entwicklung in der Reichsverfassung und seine Stellung auf.dem Westfälischen Friedenskongreß (Schriftenreihe der Vereinigung zur Erforschung der neueren Geschichte 5, 1973) S. 23-25; Armin WOLF, Die Entstehung des Kurfürstenkollegs 1198-1298. Zur 700-jährigen Wiederkehr der ersten Vereinigung der sieben Kurfürsten (Historisches Seminar NF 11, 1998) S. 48 f. und S. 162 f.; ERKENS, Kurfürsten (wie Anm. 68) S. 2. - Zur Herleitung der Verfassungsorgane aus päpstlichem Handeln: Tractatus anonymus de origine ac translatione et statu Romani imperii, hg. von Mario KRAMMER (MGH Fontes iuris 1, 1909) S. 72 f:; Gregor V. als Schöpfer in der, Determinatio compendiosa de iurisdictione imperii', die dem Tholomeus von Lucca zugeschrieben wird, ebd. S. 29 (Kap. 13) bzw. S. 59 (Kap. 29); Iohannis abbatis Victoriensis Liber certarum historiarum, hg. von Fedor ScHNEIDER, 2 Bde. (MGH SS rer. Germ. 36, 1909 f.) S. 51 f. Zur Behauptung und Zurückweisung der kurialen Entstehungslehre Irmgard LATZKE, Hofamt, Erzamt und Erbamt im mittelalterlichen deutschen Reich (Diss. Frankfurt am Main 1970) S. 269-274. Vgl. auch Bernd SCHNEIDMÜlLER, Ordnung der Anfänge. Die Entstehung Deutschlands und Frankreichs in historischen Konstruktionen des Hoch- und Spätmittelalters, in: Die Suche nach den Ursprüngen. Von der Bedeutung des frühen Mittelalters, hg. von Walter POHL (DÖAW 322 = Forschungen zur Geschichte des Mittelalters 8, 2004) S. 291-306. 
Eingehend definierte der Modus die Zusammensetzung des Parlaments aus Klerus, Laien, Baronen der fünf Häfen, Rittern der Grafschaften, Bürgern (cives) und burgenses (Kap. 2-7), um dann die Ämter des Parlaments (Kap. 8, 16, 20-22), den Ablauf der Sitzungen (Kap. 9-12, 19, 24-25) mit der Predigt „für Frieden und Ruhe des Königs und des Königreichs“ (Kap. 10) und die Verhandlungsgegenstände (Kap. 17-18) zu beschreiben. Die Bestimmungen über die Abwesenheit des Königs vom Parlament (Kap. 13) erwiesen deutlich die aus der Sicht der Teilnehmer begründete Sorge um eine monarchische Präsenz. Sie entsprach kaum dem königlichen Selbstbewusstsein, Ursprung und Ende aller Versammlungen zu sein und damit das Zusammentreten wie die Auflösung der Stände aus eigener Machtvollkommenheit regeln zu können. Hier formulierte man den Anspruch, dass das Reich seinen König zum persönlichen Auftreten zwingen könne: Unbedingt müsse der König persönlich (personaliter) am Parlament teilnehmen, wenn ihn nicht Krankheit daran hindere. Und diese dürfe nicht als unbilliger Vorwand vorgeschützt werden. Darum solle sich der kranke Herrscher in einem Zimmer am Ort des Parlaments aufhalten, damit seine körperliche Verhandlungsfähigkeit von einer Kommission aus zwölf Männern überprüft werde, von jeweils zwei Vertretern der sechs Stände. Die Abwesenheit des Königs vom Parlament sei nämlich eine verurteilungswürdige und gefährliche Angelegenheit für das allgemeine Parlament und das Königreich (absentia regis, quia res dampnosa et periculosa est toti communitati Parliamenti et regni). ${ }^{100}$

Am Ende wurden die sechs Rangstufen der ,Peers' definiert (de Gradibus Parium Parliamenti). Natürlich fiel dem König der erste Rang allein zu, da er keinen Gleichen neben sich habe. Trotz aller Sorgen um seine Präsenz (Kap. 13) erschien er hier als Haupt, Ursprung und Ende des Parlaments (Rex est caput, principium et finis Parliamenti, et ita non habet parem in suo gradu, et ita ex rege solo est primus gradus). ${ }^{101}$ Diese sechs Rangstufen erweisen allerdings eine im Vergleich zum Imperium andere aristokratische Prägung des Königreichs England, das nicht von Fürsten allein repräsentiert wurde. Im englischen Parlament des 14. Jahrhunderts kamen nicht nur der Klerus samt seinen Prokuratoren mit den Grafen, Baronen und anderen Magnaten wie Großen zusammen. Ihm gehörten auch die Ritter der Grafschaften, die Bürger und die Burgensen an.

Das für den Vergleich zur Goldenen Bulle wichtige Kapitel 14 regelte die Sitzordnung von König, Erzbischöfen, Bischöfen, Äbten, Prioren, Grafen, Baronen und Herren im Parlament und erweiterte das Ensemble um ein ganz entscheidendes Element.

\footnotetext{
100 Parliamentary Texts (wie Anm. 95) S. 72 (Rec. A) und S. 111 f. (Rec. B) (Kap. 13); ClARKE, Medieval Representation (wie Anm. 95) S. 378.

101 Parliamentary Texts (wie Anm. 95) S. 78 (Rec. A) und S. 109 f. (Rec. B) (Kap. 26); ClARKE. Medieval Representation (wie Anm. 95) S. 384.
} 


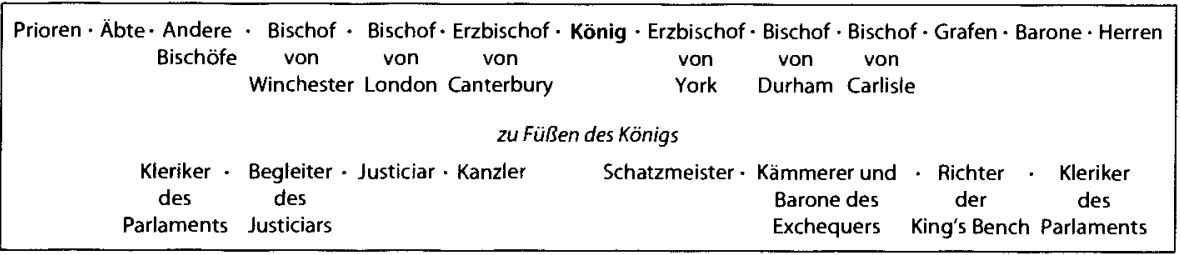

Abbildung 9

Die Sitzordnung des englischen ,Modus tenendi parliamentum'

Linealiter sollte man sitzen, nach fester Ordnung, jeweils im Kreis der pares. Dem König fiel der zentrale mittlere Platz in der größeren Bank zu. Zu seiner Rechten saßen in einer Reihe der Erzbischof von Canterbury, die Bischöfe von London und Winchester, dann die anderen Bischöfe, Äbte und Prioren. Zu seiner Linken befanden sich in einer Reihe der Erzbischof von York, die Bischöfe von Durham und Carlisle, dann seriatim die Grafen, Barone und Herren. Stets müsse man nach dieser Ordnung sitzen, damit sich niemand woanders als unter seinesgleichen befinde. Darauf solle der Seneschall Englands achten, wenn nicht der König einen anderen dafür bestimme. Anders als die Goldene Bulle band der Modus freilich die Spitze der monarchischen Verwaltung in diese Raumkonfiguration ein. Zu Füßen des Königs saßen rechts der Kanzler, der Justiciar mit seinen Begleitern und deren Klerikern des Parlaments, links dann der Schatzmeister, die Kämmerer und Barone des Exchequer und die Richter der King's Bench mit ihren Klerikern des Parlaments. ${ }^{102}$

Auch der Modus ritualisierte die politische Entscheidungsbildung, Spiegel eines besonderen Miteinanders von König, Klerus, Adel und Verwaltung. In den verschiedenen Inszenierungen einer hocharistokratischen Spitze im Imperium, einer sich öffentlich konsensgestützt präsentierenden Erbmonarchie in Frankreich und eines ausgehandelten politisch-administrativen Kräfteensembles in England greifen wir unterschiedliche Konzepte monarchischer Vielfalt im spätmittelalterlichen Europa. Diese wandelte sich beständig, erfuhr aber in den hier vorgeführten Präskripten punktuelle Systematisierung und Formalisierung. Eine ausgreifende Sammlung und Einbeziehung weiterer Sitz- und Prozessionsordnungen wäre lohnend und würde unser Wissen von gezielten Inszenierungen des politischen Ensembles und damit der Typenvielfalt spätmittelalterlicher Ordnungen erheblich bereichern.

Solche Inszenierungen vollzogen sich aber nicht nur in Wörtern und Figuren, sondern stärker noch in Bildern. Trotz des ,iconic turn' der letzten Jahre fehlen uns verlässliche Corpora für die bildlichen Konfigurationen von Reich und Herrschaft

102 Parliamentary Texts (wie Anm. 95) S. 72 f. (Rec. A) und S. 112 (Rec. B) (Kap. 14); ClARKE, Medieval Representation (wie Anm. 95) S. 379. 
im späteren Mittelalter. Forschungsperspektiven können nur in knappen Strichen angedeutet werden: In Frankreich konzentrierten sich die historisch-politischen Illuminationen der ,Grandes Chroniques de France' ganz wesentlich auf die agnatische Herrscherlinie seit trojanischen Anfängen. ${ }^{103}$ Im Imperium entwickelte sich dagegen eine bunte Bilderwelt mit Darstellungen von Königen, Kurfürsten und Gliedern des Reichs. Auch hier wurde kräftig inszeniert, in Wappenprogrammen an Brunnen, Rathäusern oder Kirchen, in Figurenzusammenstellungen in illuminierten Handschriften und Frühdrucken. ${ }^{104}$ Hartmann Schedels Weltchronik bot das Reich als symbolisches Personenensemble. Quaternionenbilder des 15. und 16. Jahrhunderts versammelten die Glieder des Reichs in Wappenbildern auf den Schwingen des Adlers. ${ }^{105}$ Solche Fokussierungen in Momentaufnahmen fingen die verschiedenen Ritualisierungen politischer Willensbildung im spätmittelalterlichen Europa ein. Sie verdienen unter Einbeziehung weiterer Reiche und Verbände eine ebenso dokumentierende wie vergleichende Bearbeitung, die durch Blicke auf die Politikgestaltung in vormodernen außereuropäischen Gesellschaften noch gewinnen könnte.

\section{Zum Schluss: Alles nur Theater?}

Nicht erst Perspektiven moderner Kulturwissenschaften legen diese Frage nahe, sondern bereits die mittelalterlichen Quellen mit ihren dezidierten Berichten von Aufführungen und Inszenierungen. Freilich war den mittelalterlichen Schreibern die neuzeitliche Scheidung von Fakt und Fiktion, von Sein und Schein fremd. Fast notgedrungen fielen die spätmittelalterlichen Vorschriften und Berichte darum einem modernen Aufführungsverdacht zum Opfer. Aber wir erkennen heute wieder deut-

103 Gert MELVILLE, Geschichte in graphischer Gestalt. Beobachtungen zu einer spätmittelalterlichen Darstellungsweise, in: Geschichtsschreibung und Geschichtsbewußtsein im späten Mittelalter, hg. von Hans PATzE (VuF 31, 1987) S. 57-154. Eine eingehende Untersuchung dieser arbores consanguinitatis wie der französischen Königslisten mit ihren Ursprüngen in trojanischer Zeit steht noch aus. Vgl. die eindrucksvollen Bilder in: Die Bilder der Grandes Chroniques de France. Mit der originalen Wiedergabe aller 51 Miniaturen von Manuscrit français 6465 der Bibliothèque nationale in Paris und 60 Schwarzweiß-Abbildungen, bearb. von François AVRIL / Marie-Thérèse GousSET / Bernard GUENÉE (1987).

104 Liselotte E. SAuRMA-JELTSCH, Das mittelalterliche Reich in der Reichsstadt, in: HeiligRömisch - Deutsch (wie Anm. 55) S. 399-439; Die Repräsentation der Gruppen (wie Anm. 22).

105 Ernst SCHUBERT, Die Quaternionen. Entstehung, Sinngehalt und Folgen einer spätmittelalterlichen Deutung der Reichsverfassung, ZHF 20 (1993) S. 1-63. 
licher die integralen Zusammenhänge, ohne doch die spätmittelalterlichen Perzeptionsebenen völlig im Griff zu haben.

Der methodische Ansatz, aus Inszenierungen oder Ritualisierungen Einblicke in gesellschaftliche Strukturierungen und Ordnungsmuster zu erhalten, bietet aktuellen kultur- wie sozialwissenschaftlichen Diskussionen entscheidende Korrekturen und Impulse. Die soziologische Modellbildung ging lange von unumkehrbaren Entwicklungen auf die Moderne aus. Darum unterschied Jürgen Habermas auf Grund zunehmender Komplexität wie Partizipation die neuzeitliche Öffentlichkeit von einer funktional auf Repräsentation radizierten Öffentlichkeit der Vormoderne. ${ }^{106}$ Sein Konzept rief mittlerweile kontroverse Diskussionen hervor. Vor allem wurde verkannt, dass entscheidende große Konflikte vom 12. bis zum 15. Jahrhundert (Schismen, Konziliarismus) nur durch das Funktionieren einer informellen europäischen Öffentlichkeit gelöst werden konnten.

Auch Niklas Luhmann entwickelte Gedanken zur überwundenen Semantik Alteuropas und differenzierte zwischen Repräsentation und Partizipation im späten Mittelalter: „Der eine Begriff denkt von oben nach unten, der andere von unten nach oben. " ${ }^{107}$ Natürlich geht Luhmann - anders als Habermas - nicht von entwicklungsgeschichtlichen Teleologien aus. Aber er baut sich seine Vorstellungen über das Mittelalter dennoch als Gegenbild zunehmender Differenzierung auf, wenn er dieser Epoche die Möglichkeit zum einheitlichen und umfassenden Politikkonzept abspricht. Der kritische Mediaevist, der entscheidende Unterschiede zwischen Mittelalter und Neuzeit in den kommunikativen Reichweiten, sozialen Differenzierungen oder theoretischen Abstraktionen in Rechnung stellt, beklagt bei Luhmann aber einen segmentierenden historischen Zugriff im Sinne verstörend willkürlich konstruierter Gegenmodelle. Dabei wird ein Mittelalter konstruiert, von dem sich eine antithetisch konturierte Moderne unterscheiden dürfte.

Die Besonderheiten der in diesem Beitrag untersuchten Phänomene des 14. Jahrhunderts beruhten dagegen auf der Verschränkung von inszenierter Repräsentation und gelebter Partizipation. Die Unterschiede zum späteren Parlamentarismus sind evident. Der aktuelle Diskurs zwischen Historikern und Soziologen leidet häufig unter den stereotypen Behauptungen von Mediaevisten, vieles sei im Mittelalters schon längst ausgebildet. Auf dieses, War schon immer da' kommt es aber ebenso wenig an wie auf anthropologische Verschmirgelungen der Zeiten. Es geht vielmehr um die Erkenntnis differenzierter Komplexitäten in verschiedenen Ausprägungen

\footnotetext{
${ }^{106}$ HABERMAS, Strukturwandel (wie Anm. 22) S. 58 ff.

107 Niklas LuHMANN, Die Gesellschaft der Gesellschaft 2 (suhrkamp taschenbuch wissenschaft 1360, 1998) S. 921.
} 
und Jahrhunderten, die in ihren Wertigkeiten ausgehalten und nicht mehr emisch abgeschichtet werden müssen.

Darum bietet jetzt der neuere ethnologische Blick auf die eigene Vergangenheit neue Chancen, Inszenierungen oder Rituale nicht mehr als endlich überwundene Kulturtechniken zivilisatorischer Rückständigkeit zu studieren. Das soziologische ,Projekt der Moderne' im Sinne eines in die Zukunft verlängerten stetigen Entwicklungsprozesses von intellektueller Systematisierung und praktizierter Entsinnlichung, gründend auf westlichen Deutungshoheiten für die Weltgeschichte, gerät derzeit an sein Ende. Der neue Rückgriff auf ältere ethnosoziologische und ritualtheoretische Ansätze ist darum kein Zufall. ${ }^{108}$ Er begreift Geschichte nicht mehr als kontingenten Veredelungsprozess der Menschheit, sondern belässt sowohl den früheren als auch den anderen anthropologischen Realitätsbewältigungen ihren eigenen Wert. In solche Debatten müssen sich die Historiker mit den Ethnologen einmischen. Sie werden das nicht mehr nur in ihrer bewährten Epochen- oder Europazentrik leisten können, sondern dürfen auch den Welten der Alten ihre eigene Würde verleihen.

Dieser Beitrag will - aus laufenden Arbeiten zur Ritualdynamik - nur erste Anstöße dazu liefern. Wir erkannten im 14. Jahrhundert den Willen zur Formulierung umfassender Ordnungsmodelle, die auf die nach innen wie außen zielende Wirksamkeit von Zeremonien und Ritualen vertrauten. Wenn der Handlungsverbund von Haupt und Gliedern in öffentlicher Darbietung saß, schritt, speiste, diente, dann erstand das Reich, in repräsentativer Vertretung wie als gelebtes Abbild, materiell wie imaginär. Der Aufzug der wenigen brachte das Ganze hervor. Alle sahen es, erlebten es, fühlten es, hörten es. Den Gebildeten des späten Mittelalters konnte man das Reich oder den Staat vielleicht juristisch wie philosophisch vermitteln oder in komplexen Lehrgebäuden erklären - die meisten Menschen aber erkannten das erst beim Hinschauen, begriffen es in Statik wie Aktion. Die Goldene Bulle stiftete als Politikentwurf Sinnhaftigkeiten, die angemessene Fügung der Zeichen, den Glanz der Repräsentation, die Fantasie der Ordnungen - all das, was in modernen Verfassungsdiskursen jenseits der Menschen manchmal zu zerrinnen droht. 1356 stellte man noch die Menschen in einen Raum und schrieb keine 1500 Seiten voller Wörter über Identitätsverordnung, wie das der zu Beginn des 21. Jahrhunderts in freien Volksabstimmungen verworfene Entwurf einer Europäischen Verfassung tat. Seinen guten Willen stellte die Mehrheit nicht in Abrede, sondern nur seinen Nutzen für das Leben.

108 Ritualtheorien. Ein einführendes Handbuch, hg. von Andréa BELLIGER / David J. KRIEGER (1998); Die Welt der Rituale (wie Anm. 69); Theorizing Rituals 1: Issues, Topics, Approaches, Concepts, hg. von Jens KreINATH / Jan SNOEK / Michael STAusberg (Studies in the History of Religions 114, 2006). 
Vor zwei Jahrhunderten, in ,Dichtung und Wahrheit', erzählte Goethe von seinen Erinnerungen an Wahl und Krönung Kaiser Josephs II. in Frankfurt am Main. Für Goethe entstand bei allen altertümlichen Wunderlichkeiten gerade in der körperlichen Inszenierung der Zauber des Reichs: Einerseits hatte ich an diesen Dingen manche Lust: weil alles was vorging, es mochte sein von welcher Art es wollte, doch immer eine gewisse Deutung verbarg, irgend ein innres Verhältniß anzeigte, und solche symbolische Ceremonien das durch so viel Pergamente, Papiere und Bücher beinah verschüttete Deutsche Reich wieder für einen Augenblick lebendig darstellten. ${ }^{109}$

Lebendigkeit - das war die eigentliche Leistung der geschriebenen und gelebten Inszenierungen und Rituale im 14. Jahrhundert. An der Fähigkeit zur Vitalität muss sich jede formalisierte Politikgestaltung in Geschichte, Gegenwart und Zukunft messen lassen.

109 Johann Wolfgang GOETHE, Aus meinem Leben. Dichtung und Wahrheit, in: Goethes Werke, hg. im Auftrage der Großherzogin Sophie von Sachsen, 133 Bde. in IV Abt. (1887-1919), hier I 26 S. 290. Vgl. Heinz Georg HELD, Ritualästhetik. Goethes Ekphrase der Frankfurter Krönungszeremonien von 1764, in: Investitur- und Krönungsrituale. Herrschaftseinsetzungen im kulturellen Vergleich, hg. von Marion STEINICKE / Stefan WeINFURTER (2005) S. 447-473; Die Kaisermacher. Katalog (wie Anm. 4). Über Symbolik und Realität am Ende des Alten Reichs Barbara StollBERG-RILINGER, Das Heilige Römische Reich Deutscher Nation. Vom Ende des Mittelalters bis 1806 (2006). 